\title{
Implication of the p53-Related miR-34c, $-125 b$, and -203 in the Osteoblastic Differentiation and the Malignant Transformation of Bone Sarcomas
}

\author{
Camille Jacques, Robel Tesfaye, Melanie Lavaud, Steven Georges, Marc Baud'huin, \\ François Lamoureux and Benjamin Ory * \\ INSERM, Bone sarcomas and remodeling of calcified tissues, Nantes Université, UMR 1238, \\ F-44000 Nantes, France; cjacques44000@gmail.com (C.J.); robel.tesfaye@etu.univ-nantes.fr (R.T.); \\ melanie.lavaud@etu.univ-nantes.fr (M.L.); Steven.Georges1@univ-nantes.fr (S.G.); \\ marc.baudhuin@univ-nantes.fr (M.B.); francois.lamoureux@univ-nantes.fr (F.L.) \\ * Correspondence: Benjamin.ory@univ-nantes.fr; Tel.: +33-272-641-142
}

Received: 28 February 2020; Accepted: 25 March 2020; Published: 27 March 2020

\begin{abstract}
The formation of the skeleton occurs throughout the lives of vertebrates and is achieved through the balanced activities of two kinds of specialized bone cells: the bone-forming osteoblasts and the bone-resorbing osteoclasts. Impairment in the remodeling processes dramatically hampers the proper healing of fractures and can also result in malignant bone diseases such as osteosarcoma. MicroRNAs (miRNAs) are a class of small non-coding single-strand RNAs implicated in the control of various cellular activities such as proliferation, differentiation, and apoptosis. Their post-transcriptional regulatory role confers on them inhibitory functions toward specific target mRNAs. As miRNAs are involved in the differentiation program of precursor cells, it is now well established that this class of molecules also influences bone formation by affecting osteoblastic differentiation and the fate of osteoblasts. In response to various cell signals, the tumor-suppressor protein p53 activates a huge range of genes, whose miRNAs promote genomic-integrity maintenance, cell-cycle arrest, cell senescence, and apoptosis. Here, we review the role of three p53-related miRNAs, miR-34c, $-125 b$, and -203 , in the bone-remodeling context and, in particular, in osteoblastic differentiation. The second aim of this study is to deal with the potential implication of these miRNAs in osteosarcoma development and progression.
\end{abstract}

Keywords: bone; osteosarcoma; microRNAs

\section{Introduction}

Bone is a highly dynamic structure that has both biomechanical and biologic functions, as it protects the inner organs, furnishes muscle attachment, provides calcium and phosphorus reservoirs, and assumes hematopoietic functions. Bone remodeling is an important process, starting in the embryo and continuing throughout the entire life of vertebrates. It allows the bone-mass to stay constant through the antagonist-balancing activities of the two kinds of bone-related cells: the bone-forming osteoblasts and the bone-resorbing osteoclasts. Impairments in these balanced activities may result in osteo-condensing bone pathologies such as osteopetrosis or osteolytic metabolic lesions, like osteoporosis, and can also be the origins of bone cancers. Malignant bone diseases are rare pathologies fueled by the establishment of a vicious cycle between the tumor cells and the above-mentioned bone-specialized cells. With an incidence of four to five cases per million and a peak at around 18 years of age, osteosarcoma is by far the most common type of these neoplasms [1,2]. The suspected initiated cell in this pathology is the osteoblast [3], and even if, to date, no specific genetic lesion has been uncovered to characterize this pathology, the locus of the tumor suppressor gene $p 53$ is altered in about 
$50 \%$ of patients $[4,5]$. This cancer is most often localized on the metaphysis of the long bones of the extremities, namely, the distal femur, the proximal tibia, and the proximal humerus [6]. Despite recent progress in the therapeutic management of osteosarcomas, the survival rates have not increased in two decades. Thus, to improve the outcome of this pathology, a better understanding of the mechanisms governing the osteoblastic differentiation, the bone-remodeling processes, and, more generally, the carcinogenesis of this cancer are still needed. Worthy of note is that it is now well-established that epigenetic mechanisms such as those implicating the small regulatory microRNAs (miRNAs) are of paramount importance to the control of such processes and to the consequent initiation and malignant progression of osteosarcomas.

Since the discovery of the first miRNA, lin-4, implicated in the development of the microscopic worm C. elegans [7], it has been well-established that these evolutionarily conserved molecules add a novel complex epigenetic regulation layer to the control of gene expression. MiRNAs are small non-coding RNAs of about 22-24 nucleotides in length that disrupt gene expression of messenger RNAs (mRNAs) through the base-pairing in their $3^{\prime}$-untranslated regions (UTR). Depending on their target sequence homology, they induce either translational repression or mRNA degradation and, consequently, lower the levels of target proteins. Bioinformatics analysis reveals that more than $30 \%$ of human genes could be regulated by miRNAs [8]. Because a unique miRNA is sometimes able to target more than a hundred of different mRNAs [9], such regulators can powerfully balance complex networks and constitute critical control nodes in response to the cell environment. In recent years, intensive research has highlighted their implication in various biological processes such as proliferation, cell cycle control, differentiation, or apoptosis. Additionally, they were found to be aberrantly deregulated in a number of diseases, including cancers. Evidence of a relevant implication of miRNAs in cancers was reported for the first time in 2002, after the observation that the miR-15a and -16-1 were often down-regulated or deleted in chronic lymphocytic leukemia cancers [10]. It is worth noting that some miRNAs down-regulate genes with oncogene properties and have, in this case, a tumor suppressor role. On the other hand, some others directly target tumor-suppressor genes and are called oncomiRs. To effectively mediate their inhibitory role, several maturation steps of these molecules are needed. The RNA polymerase II (RNA pol II) is the first player in miRNA biogenesis, allowing for the transcription of a hairpin-structured primary-transcript (pri-miRNA). The latter is then cleaved by the endonuclease III complex DROSHA/DGCR8, leading to a 70-nucleotide length pre-miRNA. The generated pre-miRNA is then exported out of the nucleus by the Exportin- 5 before undergoing a second maturation step assumed by the endoribonuclease DICER, producing the mature miRNA. The latter is finally carried by the AGONAUTE slicer-complex to form an active inhibitor-featured structure termed the miRNA-induced silencing complex (RISC). Considering the fact that the miRNA's promoters bear a close resemblance to those of the protein-coding genes, the expression of these small regulators is modulated by the same regulating processes and, thus, is under the control of a plethora of transcription factors such as $\mathrm{p} 53$.

The TP53 gene, encoding the p53 protein, is certainly the most famous tumor-suppressor gene in the field of cancer biology due mainly to its genome-safeguard properties. The p53 family is composed of three sequence-specific transcription factors, p53 itself, p63, and p73, regulating the expression of a variety of direct target genes implicated in DNA repair, the induction of cell-cycle arrest, cell senescence, and apoptosis [11,12]. The tumor-suppressor functions of p53 are, moreover, supported by the fact that over $50 \%$ of human cancers display mutation or inactivation in this gene $[13,14]$. In addition, such mutations or deletions have been associated with Li-Fraumeni syndrome and a predisposition to developing a wide range of tumors including osteosarcomas $[15,16]$. Various cellular stresses such as DNA damage, hypoxia, nutrient deprivation, or $\gamma$-irradiation serve as stimuli that are integrated by p53, allowing for its stabilization and, consequently, ensuring both its nuclear translocation and its binding to the promoters of its target genes [17].

In the bone-related concerns of this review, the role of p53 in controlling both apoptosis and cell growth has been shown to be crucial to the preservation of bone homeostasis. It was 
reported that p53-mutated mice, in which p53 activity is increased, displayed a particular early-aged osteoporotic phenotype [18]. On the other hand, the $\mathrm{p} 53^{--}$mice model was reported to harbor a high bone-mass phenotype. These data are in accordance with other publications reporting the anti-osteoblastic-differentiation role of p53 [19]. It is now well established that p53 counteracts bone remodeling, primarily by impairing the osteoblastic differentiation program driven by two pivotal osteoblastic-related transcription factors: RUNX2 (runt-related transcription factor 2) and Osterix [20]. Both are essential cooperating factors in osteoblastic differentiation, and the expression of the zinc fingers that contain factor Osterix is controlled by RUNX2, as its expression was abrogated in RUNX2-null mice [21]. The role of p53 in osteoblastic differentiation is due not only to its transcription factor properties but it also has been demonstrated to repress the expression of Osterix in a promoter-binding independent manner [20]. In the same study, investigators showed that $\mathrm{p} 53^{-/-}$mice display increased bone mineral density and that $\mathrm{p} 53^{--}$osteoblasts exhibit accelerated differentiation. By using MDM2 (mouse double minute 2 homologue)-conditional Col3.6-Cre mice, in which the conditional deletion of the p53 inhibitor MDM2 is allowed in osteoblasts, Lengner et al. showed that the negative regulation exerted by MDM2 on p53 is required for proper osteoblastic differentiation [22]. Additionally, in these cells, alkaline-phosphatase (ALP), osteocalcin (OCN), and type I collagen (Coll-I) expression did not display the increase normally observed in wild-type osteoblast progenitor cells during maturation. Another study reported that embryonic fibroblasts from $\mathrm{p} 53^{--}$mice express high levels of RUNX2 and Osterix as well as exhibit higher basal- and BMP4-induced ALP activity as compared to normal fibroblasts [23]. In addition, the siRNA-mediated or genetic null mutation-mediated knock-down of p53 in osteoblasts from mice calvarias results in an increased expression of RUNX2 [24]. On the other hand, the induction of p53 by either $\gamma$-irradiation, by inhibiting the expression of MDM2 by treatment with its pharmacological inhibitor Nutlin-3, or through the conditional expression of its cellular inhibitor p14/p19ARF all result in a decrease in the expression of RUNX2 at the protein level. Interestingly, a feed-back regulation loop was also demonstrated by Ozaki et al., who found that RUNX2 was a p53 inhibitor (Figure 1) [25].

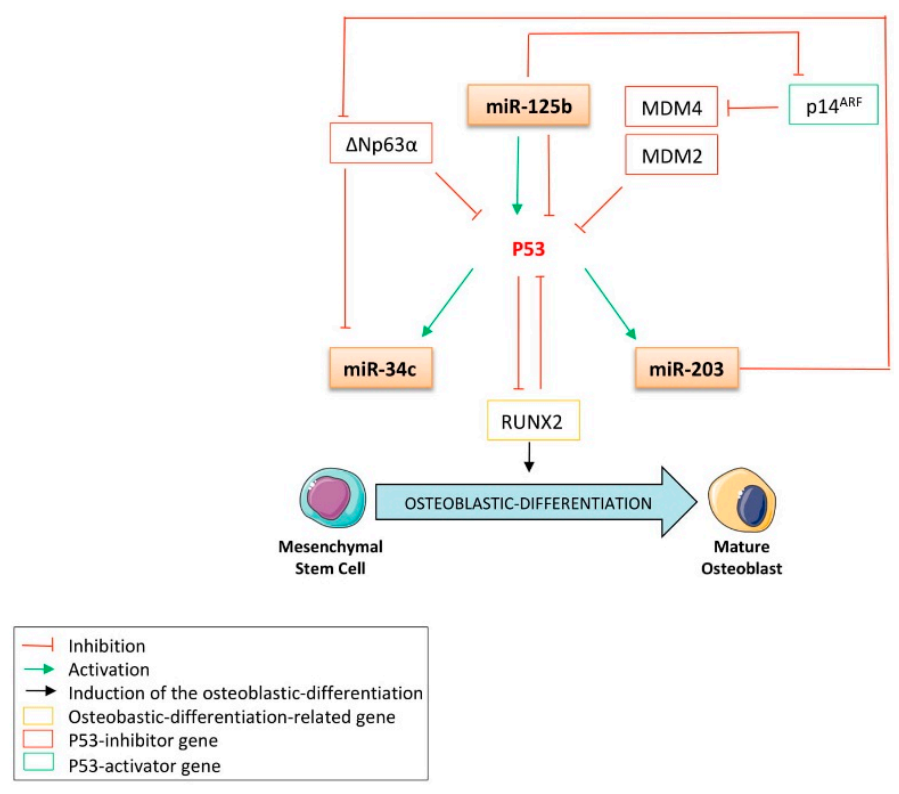

Figure 1. The relationship among p53, the p53 activators, the p53 inhibitors, and the miR-34c, $-125 b$ and -203 is essential to control the osteoblastic differentiation. MDM2: mouse double minute 2 homologue; MDM4: mouse double minute 4 homologue; RUNX2: runt-related transcription factor 2.

Beyond the direct transcriptional activity of p53, its ability to induce the expression of miRNAs confers on it a novel, indirect, negative regulation power over gene expression. It thus broadens our knowledge about its tumor-suppressive activity, especially as it has been well documented that 
several p53-related miRNAs are implicated in cancer outset, promotion, and extent. In addition, the recent breakthroughs in the field of cell-fate-determination research have progressively integrated the miRNAs as key modulators of osteoblastic differentiation (e.g., miR-138 and -206, which have already been described as inhibitors of this process $[26,27])$. In line with this consideration, this review aims to focus on three interesting p53-related miRNAs: miR-34c, $-125 b$, and -203 . Their direct and indirect involvement in both osteoblast biology and tumorigenesis are studied and provide a novel glimpse at the indirect implications of p53 in the development of osteosarcoma.

\section{The Expression of miR-34c and -203 Is Controlled by p53}

\section{1. $M i R-34 c$}

\subsubsection{MiR-34c and Cancer: Generalities}

MiR-34c belongs to the miR-34 family, which encompasses three members of vertebrates: miR-34a, transcribed from a large transcriptional unit on chromosome $1 \mathrm{p} 36$, and miR-34b and $-34 \mathrm{c}$, which are both co-transcribed from the chromosome 11q23 [28]. An expansive body of literature shows that miR-34c is often subjected to severe down-regulation in various cancer models, such as nasopharyngeal carcinomas [29], laryngeal carcinomas [30], colon adenocarcinomas [31], uveal melanomas [32], gliomas [33], prostate cancers [34], and osteosarcomas [24]. Such down-regulation could be partially explained by epigenetic mechanisms, as the $\mathrm{CpG}$ islands of miR-34c's promoters were found to be hypermethylated in, for instance, colorectal cancers [35,36], gastric cancers [37], and myeloproliferative neoplasms [38]. In addition, the aberrant hypermethylation of the miR-34c's promoter is correlated with a high probability of the recurrence of stage- 1 non-small-cell lung cancer (NSCLC) and is also associated with poor overall survival and low disease-free survival [39]. Interestingly, some other studies report that, on the other hand, miR-34c is overexpressed in squamous cell carcinomas of the tongue [40], high-grade cervical intraepithelial neoplasms [41], and cancer stem cells of hepatocellular carcinomas [42]. Nevertheless, as quiescence is a bona fide stem cell property, the overexpression of this miRNA in the latter models could finally contribute to sustaining the dormant steady state of those cells and, thus, impair the pro-proliferative pathways instead of serving as an oncogene signature. Nonetheless, all these contradictory studies remind us that, given the multiple targets of a single miRNA, its role in whole integrated systems depends on the cell type, the cellular context, and, obviously, environmental factors. In this regard, as miR-34c seems to be a key player in the maintenance of the normal cell's phenotype, its expression must be subjected to tight control.

\subsubsection{The Expression of miR-34c Is Directly Induced by p53}

A large body of evidence reports that the expression of miR-34c is fine-tuned by several tumor-suppressive pathways, such as the p53 pathway (Figure 1). By performing chromatin immunoprecipitation (ChIP) assays after the induction of DNA damage in wt- or $\mathrm{p} 53^{-/-}$murine embryonic fibroblasts, He et al. became the first to report that miR-34's family is a direct transcriptional target of p53 [43]. This group found that the promoter of miR-34's family contains a palindromic sequence matching the canonical p53-binding site. Such results were soon afterward extended in colon adenocarcinomas cells by Bommer et al., who characterized the direct role of p53 in the transcription of miR-34c by monitoring miR-34b/c promoter-activity via luciferase reporter assays in cells transfected with wt or mutant p53 [44]. They found that the luciferase activity was significantly enhanced only after transfection of the wt form of p53. In addition, Corney et al. performed miRNA microarrays and RT-qPCR analysis and reported a twelve-fold decrease in miR-34c expression after the conditional inactivation of p53 in cells from the mouse ovarian epithelium [45]. These investigators also found that the expression of this miRNA is lost in human ovarian-adenocarcinoma p53-null cells. Such results are in accordance with those of Kumamoto et al., who found that treating fibroblasts with the MDM2 inhibitor Nutlin-3a increases the expression of p53 and the expression of its target genes, 
including miR-34c, thus inducing cell senescence [46]. Additionally, the authors showed that the up-regulation of this miRNA does not occur in cancer cell lines harboring neither a null nor a mutant p53 protein. He et al. further confirmed these results in a bone cancer model, as both $\gamma$-irradiation or an Adriamycin treatment strongly induce miR-34c expression in the U2OS p53-wt osteosarcoma cell line but not in the SaOS-2 p53-null one [47]. The authors also showed that transfecting this miRNA in these cell lines induced a G1 phase cell-cycle arrest, while annexin-V staining revealed a more potent induction of apoptosis in wt-p53 cells than in p53-null cells. More recently, the ChIP assays from Fabbri et al. confirmed the p53-transactivating activity on miR-34c in a leukemia model [48]. Another interesting proof of the miR-34c's bona fide role as a tumor suppressor is that it is inhibited by the p53 inhibitor $\Delta \mathrm{Np} 63 \alpha$. Indeed, the study of Antonini et al., performed in a primary mouse keratinocyte model, revealed that $\Delta \mathrm{Np} 63 \alpha$ directly binds to the p53-consensus binding site of the miR-34c promoter, leading to the inhibition of the activity of this promoter [49]. Together, this data supports the notion that miR-34c's family is a p53 transcriptional target and advocates for the tumor-suppressive role of this miRNA, which will be further developed in this review.

\section{2. $M i R-203$}

\subsubsection{MiR-203 and Cancer: Generalities}

Similar to miR-34c, miR-203 is often subjected to deregulation in several malignancies and is undoubtedly linked to crucial processes affecting cancer induction and spreading. MiR-203 is reported to be down-regulated in esophageal cancers [50,51], melanomas [52], basal cell carcinomas [53], cervical intraepithelial neoplasias [41], and bone metastasis from prostate cancers [54]. In addition, the promoter region of this miRNA was found to be hypermethylated in multiple myelomas [55], rhabdomyosarcomas [56], hepatocellular carcinomas [57], oral squamous cell carcinomas [58], prostate cancers [59], myeloproliferative neoplasms [38], cervical cancers [60], nickel-transformed bronchial epithelial cells [61], and hematopoietic malignancies [62]. By contrast, the expression of miR-203 is increased in colon adenocarcinomas [31] and bladder cancer models [63]. Of note, its role has been well-studied throughout the course of epidermal differentiation, as it is one of the most overexpressed miRNAs in keratinocytes [64].

2.2.2. P53 and miR-203, an Indirect Interplay: The Expression of miR-203 Is Indirectly Induced by p53 and miR-203 also Indirectly Regulates p53

Although a plethora of evidence indicates that p53 is an inducer of the miR-34c family's expression, only an indirect regulation of miR-203 by p53 has been reported. Suzuki et al. were the first to highlight this indirect regulation, as they found that a Doxorubicin treatment increases p53 expression as well as that of miR-203 in the human colon cancer cell line HCT116 (Figure 1) [65]. In accordance with these results, a down-regulation of miR-203's expression was observed after either a p53 knock-down or a p53 degradation by the human papillomavirus type 16 (HVP16) oncoprotein E6, in a human foreskin fibroblast model [66]. This group has also shown that the introduction of the wt-p53 gene into the p53-null human lung cancer cell line H1299 leads to an increase in miR-203, whereas a p53-mutated introduction does not. These results thus confirm that the expression of miR-203 is dependent on the proper transcriptional activity of p53. In addition, the expression of miR-203 correlates with the level of DNA-damage response induced by either Ultra violet radiation [67] or doxorubicin treatment [66], both of which are known to induce the activity of p53. More recently, this regulation was supported by the fact that cisplatin promotes cell death through the induction of miR-203's expression in a p53-dependent manner [68]. On the other hand, it is noteworthy that primary human lung fibroblasts transfected with the p53-inactivating peptide GSE56 display an increased expression of miR-203, suggesting, in this model, the repressive role of p53 on the expression of this miRNA [69]. Interestingly, Yi et al. highlighted another indirect feedback mechanism by which miR-203 controls the expression of p53 itself [64]. This group demonstrated that the direct targeting capabilities of miR-203 toward the 
p53 inhibitor p63 are conserved across the vertebrates, as reduced luciferase activity was obtained in a reporter construct bearing the p63-3'UTR of human, mouse, and zebrafish (Figure 1). The interesting, indirect interplay between miR-203 and both p53 and the miRNA's target genes, which will be developed further in this review, give this miRNA a central place in the context of bone remodeling.

\section{3. $M i R-125 b$}

\subsubsection{MiR-125b and Cancer: Generalities}

Located on the chromosome 11q24.1, miR-125b has been well-studied in the past. Nevertheless, its role in cancer is not well understood, as several contradictory studies report either oncogene or tumor-suppressor properties, depending on the models. It is underexpressed in medulloblastomas [70], cutaneous squamous cell carcinomas [71], osteosarcomas [72], melanomas [73], ovarian cancers [74], and the hyperproliferative keratinocytes found in psoriasis lesions [75]. On the other hand, it was also reported that reconstituted mice with modified bone marrow in which the expression of miR-125b was enforced exhibited clear myeloproliferative disorders, increasingly progressing to myeloid leukemia [76]. Furthermore, lida et al. sustained its oncogenic properties, as they found that this miRNA was up-regulated in both doxorubicin-resistant Ewing sarcoma cell lines and human tumor samples that escaped from chemotherapy [77]. Down-regulating this miRNA in such resistant cell lines sensitizes them to doxorubicin, vincristine, and etoposide, thus suggesting its implication in the regulation of a multidrug-resistance pathway. In addition, its increased expression throughout the course of human mesenchymal stem cell (MSC) differentiation into the osteoblastic lineage also implicates miRNA-125b in this process [78].

\subsubsection{MiR-125b Represses the Expression of $\mathrm{p} 53$}

To ensure a robust and proper response to the cellular environment and to suppress tumors, both the expression and the activity of p53 must be tightly controlled. Thus, several transcriptional repressors, such as the p53-related member $\Delta \mathbf{N p 6 3 \alpha}$, were previously reported to have a dominant-negative role on p53 (Figure 1) [79]. In addition, the MDM2 and MDM4 ligases are two well-known p53-post-translational inhibitors, as they induce its ubiquitination-mediated degradation [80]. Moreover, over the last decade, it has become obvious that the expression of p53 is also subjected to epigenetic mechanisms, in particular, those coordinated by the miRNAs. Additionally, miR-125b is worthy of attention in the context of this review not only because of the extensive evidence of its direct

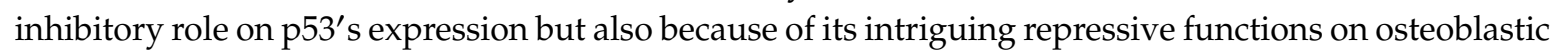
differentiation. Le et al. were the first to report that this miRNA directly targets p53's $3^{\prime}$ UTR in human lung fibroblasts and in the zebrafish brain [81]. In addition, this group demonstrated that the expression of miR-125b decreases after either camptothecin- or $\gamma$-irradiation-induced DNA damage, in accordance with the rapid p53 increase observed in response to such injuries. It was further confirmed by lida et al. that p53 was a direct target of miR-125b in Ewing sarcoma cells [77]. More recently, Amir et al. reported another indirect mechanism by which miR-125b controls the expression of p53 in a prostate cancer model [82]. This group reports that this miRNA directly targets the MDM2 inhibitor p14 ${ }^{\text {ARF }}$ and consequently inhibits the expression of p53 and its target genes, p21 and PUMA (Figure 1). Functionally, it was found that miR-125b represses the p53-induced apoptosis, as its overexpression in the human neuroblastoma SH-SY5Y cell line consequently reduces the expression of p21 and Bax, another p53-target gene [81].

\subsubsection{MiR-125b Induces the Expression of p53}

Even if miR-125b appears as a p53 inhibitor, its relationship with the guardian of the genome is not clear-cut. It is important to take note of another study reporting that a stable increase of miR-125b expression in cutaneous malignant melanoma cells leads to an increase in the expression of p53 at the protein level, further inducing cell senescence (Figure 1) [83]. The dual role of miR-125b on the 
expression of p53 is obviously highly dependent on the expression level and/or activity of p53 inhibitors and highlights, once again, the complexity and necessity of fine-tuning the expression of p53.

\section{3. p53-related miRNAs Inhibit Osteoblastic Differentiation through Their Ability to Impair the Expression of Several Bone-Related Factors}

As miRNAs are implicated in several biological processes, it seems obvious that they are also implicated in bone remodeling and the consequent pathologies associated with defects in this mechanism [84,85]. A better understanding of the implication of miRNAs in osteoblastic differentiation is essential to give rise to future clinical applications and hopefully improve the outcome of bone fractures and bone malignancies such as osteosarcoma.

\subsection{The Osteoblastic Differentiation of Multipotent Mesenchymal Stem Cells Is Controlled by Several Crucial Factors and Pathways}

Multipotent mesenchymal stem cells (MSCs) are subjected to osteoblast differentiation through several stimulating extracellular ligands such as bone morphogenetic proteins (BMPs), Wnts, oncostatin-M (OSM), interleukins (IL), and fibroblast growth factors (FGFs) (Figure 2). They first differentiate into pre-osteoblasts, which are characterized by the expression of Runt-related transcription factor 2 (RUNX2), distal-less homeobox 5 (Dlx5), and Msh homeobox homologue 2 (MSX2). They then differentiate into immature osteoblasts, expressing bone morphogenetic protein 2 (BMP2), Osterix, $\beta$-catenin, bone sialoprotein (BSP), and osteopontin (OPN). Mature osteoblasts are osteocalcin, alkaline phosphatase, and type-I collagen producers, allowing them to form mineralized bones [86]. These cells also express several osteoblast differentiation-related hormone receptors, such as the receptors for parathormone (PTH), 1 $\alpha, 25$-dihydroxyvitamin $\mathrm{D}_{3}$, estrogen, and glucocorticoids. In addition to RUNX2 and Osterix, the mature osteoblasts express several key transcription factors such as SOX9 and activating transcription factor 4 (ATF4), all required for their differentiation into the bone-associated cell lineage. It was shown that all these factors physically associate to cooperate with RUNX2 and Osterix in their transcriptional capabilities [87], suggesting that impairment in these interactions could reduce the potential of cellular differentiation. In return, these transcription factors are controlled by a series of tightly regulated pathways, which are also often deregulated in cancers, including osteosarcomas. These pathways include, for instance, the Notch, the Sonic/Hedgehog, the Wnt, the TGF- $\beta$, and the BMP and will be detailed further in this review, as impairment of them might have an indirect negative effect on osteoblastic differentiation (Figure 2).

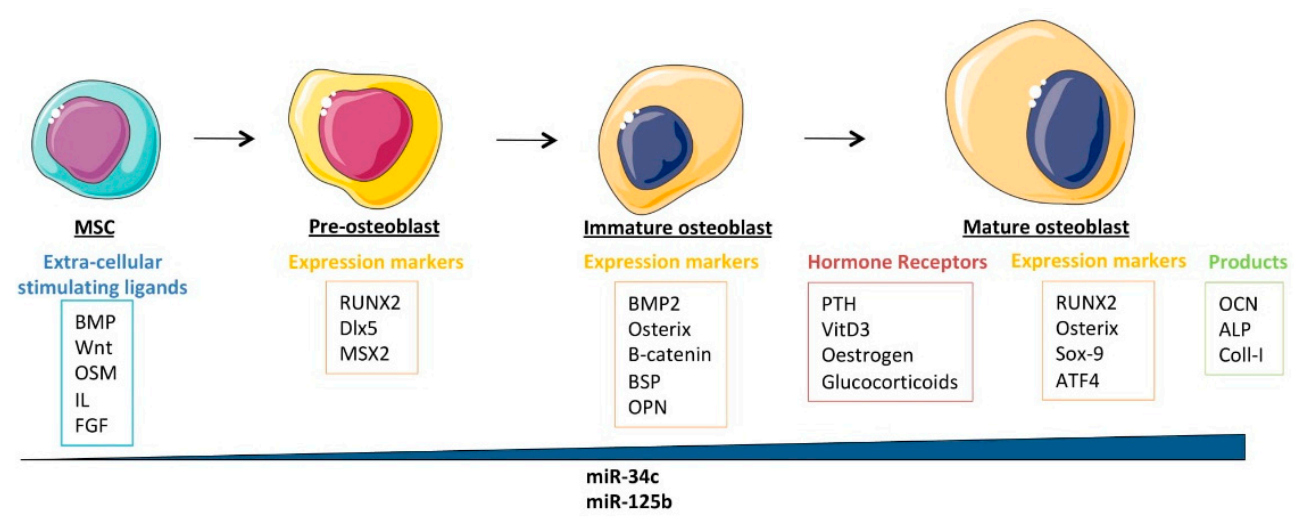

Figure 2. The osteoblastic-differentiation process; ALP: alkaline phosphatase; ATF4: activating transcription factor 4; BMP: bone morphogenetic protein; BSP: bone sialoprotein; Coll-I: type I collagen; FGF: fibroblast growth factor; IL: interleukin; MSC: mesenchymal stem cells; MSX2: Msh homeobox 2; OCN: osteocalcin; OPN: osteopontin; OSM: oncostatin M; PTH: parathormone; RUNX2: runt-related transcription factor 2 . The blue triangle represents the increased miRNA-expression level found in the cells during the course of the differentiation. 
3.1.1. The p53-Related miRNAs Regulate the Early Stages of Osteoblastic Differentiation by Controlling the Pre-Osteoblast-Specific Factor RUNX2

\section{RUNX2}

MiRNAs are crucial regulators of bone formation through their ability to attenuate signaling pathways and transcription factors' expression implicated either in osteoblastic differentiation or in their function. Among all the transcription factors related to this process, RUNX2 is one of the most-studied. It belongs to the runt-related sequence-specific transcription factor family, which encompasses three members: RUNX1, RUNX2, and RUNX3. Their runt DNA binding domain is homologous with the drosophila pair-rule gene runt [88] and confers on them the ability to associate with the co-activator core-binding factor $\beta$ (CBF- $\beta$ ) [89]. Even though RUNX2 is involved in the tightened regulation of various cellular processes, including development, tumorigenesis, and differentiation, its role has been particularly studied in osteoblastic and chondrocytic differentiation, especially in the early stages of these processes. Beyond the differentiation process, evidence also reports its implication in the proper function of osteoblasts, as it is required for both bone formation and mineralization [90]. For instance, it was reported that RUNX2 ${ }^{-/-}$mice display a lack of osteoblasts [91]. Additionally, RUNX2 was found to be overexpressed in chemoresistant osteosarcomas [92], non-small cell lung cancers (NSCLCs) [93], and breast cancers [94], thereby raising the legitimate question of its role as a tumor-driving transcription factor. The latter has not yet been clearly demonstrated but it was reported that RUNX2 contributes to the development of T-cell lymphoma through its cooperation with the oncogene c-Myc [95]. There is no evidence in the literature that p53 directly modulates the expression of RUNX2, especially as no p53-canonical binding site was found in the RUNX2 promoter sequence. Nonetheless, regarding p53's inhibitory effect on osteoblastic differentiation, the p53-regulated miRNAs able to target RUNX2 might largely be implicated in such features. Indeed, miR-34c was reported to repress RUNX2 by direct interaction, as assessed by reporter assays after modulation of the miRNA's expression level by mimic- or anti-miRNA transient transfections in mouse MC3T3-E1 osteoblasts (Figure 3) [96]. Increasing the expression of miR-34c in these cells significantly reduces the RUNX2 protein expression level but also impacts the osteoblastic differentiation markers OCN and OPN. In addition, such an increase has a functional effect on reducing ALP activity. The direct interaction between miR-34c and RUNX2-mRNA was further supported by Van der Deen's work on an osteosarcoma model [24], in which the weak expression level of this miRNA in SaOS-2 and $\mathrm{U}_{2} \mathrm{OS}$ osteosarcoma cell lines was also reported. Interestingly, Wei et al. found that the expression level of miR-34c increases during the course of the differentiation of osteoblasts from mouse calvaria [97]. By generating a transgenic mice model overexpressing miR-34c in the osteoblasts and displaying a lower mineralized bone volume over the total volume (BV/TV) compared to normal mice, this group highlighted the negative impact of miR-34c on osteogenesis. Interestingly, this group also showed that bone OCN and BSP levels were affected by the enforced expression of this miRNA in osteoblasts. Surprisingly, such conditions did not alter the expression levels of RUNX2, ATF4, Osterix, and the receptor activator of nuclear factor $\mathrm{kb}$ ligand (RANKL), an osteoblast- and osteoclast-activating cytokine.

Both miR-34c and miR-203 were reported to repress RUNX2's expression through direct interaction with the 3'UTR of the RUNX2 messenger (Figure 3) [54]. Functionally, overexpression of this miRNA in the PC3 prostate carcinoma cell line significantly reduces the expression of RUNX2 at the protein level. Interestingly, it was reported that through its RUNX2 targeting capabilities, miR-203 was able to impair the progression of breast cancer as well as reduce its bone-associated metastases [98]. 


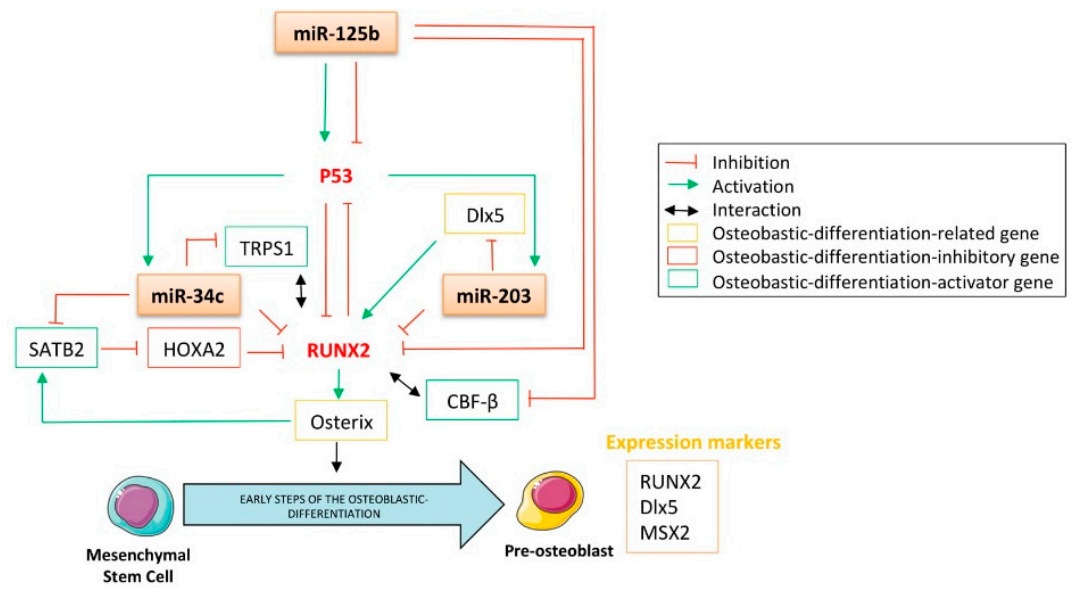

Figure 3. The direct targeting of RUNX2 and Dlx5 by the p53-related miRNAs involved them in the control of the early steps of the osteoblastic differentiation. CBF- $\beta$ : core-binding factor $\beta$; MSX2: Msh homeobox 2; RUNX2: runt-related transcripion factor 2; SATB2: Special AT-rich sequence binding protein 2; TRPS1: Tricho-rhino-phalangeal syndrome 1.

Interestingly, contradictory data was published concerning the role of miR-125b in RUNX2-expression modulation. For instance, Chen's work showed that the expression of RUNX2 increased in the thoracic aorta of rats suffering from chronic kidney disease and corresponded to a reduced expression of vascular miR-125b in this model [99]. The chronic-kidney-disease animals also displayed increased calcification of the aortic arch, negatively correlated with the miR-125b level in the thoracic aorta. These data sustain the inhibitory role of miR-125b on vascular calcification, possibly through its ability to modulate the expression of RUNX2, even if no direct targeting was exhibited here. On the other hand, another group showed no modulation in RUNX2, OPN, and ALP gene expressions subsequent to the gain or loss of miR-125b in MSCs [78]. Interestingly, these investigators reported an increase in the expression level of this miRNA during the osteoblastic differentiation of such cells. In addition, it is now well established that CBF- $\beta$ physically associates with RUNX2 to increase its DNA affinity [100], and miR-125b was precisely reported as inhibiting CBF- $\beta$-mediated osteogenesis through direct CBF- $\beta$-targeting (Figure 3) [101]. In addition, through the regulation of the proliferation of mouse mesenchymal stem cells, an inhibitory effect of miR-125b on BMP-4-induced osteoblastic differentiation was highlighted [102]. This study reported a decrease in the expression of the OCN transcript, as well as reduced ALP activity after miR-125b's transfection into ST2 and NRG stem cells. By assessing the matrix mineralization capabilities of calcifying human coronary artery smooth muscle cells (HCASMCs), their RUNX2 mRNA expression level, as well as their ALP mRNA expression level and activity, Goettsh et al. found that the inhibition of endogenous miR-125b promotes osteogenic differentiation [103]. In addition, investigators noticed a significant up-regulation of Osterix at both mRNA and protein levels when miR-125b was inhibited in calcifying HCASMCs.

Additionally, even if RUNX2 is a key player in osteoblastic differentiation, it does not drive the entire process by itself [104]. Thus, in a differentiation control context, the multi-targeting capabilities of the above-mentioned p53-related miRNAs seem to be of particular interest. Numerous other nuclear factors also cooperate with RUNX2 to elicit osteoblastic differentiation, for example, special AT-rich sequence binding protein 2 (SATB2), the homeobox transcription factor Dlx5, and the tricho-rhino-phalangeal syndrome I factor TRPS1 [105]. Their targeting by these miRNAs and the consequent effect on both the expression and activity of RUNX2 might impede osteoblastic differentiation (Figure 3).

Special AT-Rich Sequence Binding Protein 2 (SATB2)

Special AT-rich sequence binding protein 2 (SATB2) is a member of the special AT-rich binding protein family, characterized by its ability to bind to the so-called nuclear matrix attachment regions 
(MARs) to further modulate the chromatin structure and, consequently, impact gene transcription. It has been reported to be an osteoblastic differentiation marker [106,107], and Osterix was shown to directly regulate its transcription [108]. The effect of SATB2 on the regulation of osteoblastic differentiation is partially explained by its inhibitory effect on the RUNX2 inhibitor Hoxa2, consequently resulting in increased activity of both RUNX2 and activating transcription factor 4 (ATF4) $[109,110]$. Wei et al. reported that miR-34c directly binds to the 3'UTR of SATB2 to down-regulate its expression, resulting in an inhibition of both the proliferation and the differentiation of mice osteoblasts (Figure 3) [97].

\section{The Homeodomain-Containing Transcription Factor Dlx5}

The homeodomain-containing transcription factor Dlx 5 is a member of the evolutionary conserved Dlx homeobox gene family, which encompasses six genes organized into bi-genes clusters: Dlx1/2, Dlx5/6, and Dlx3/7. Such genes are homologous to the Distal-less $(D l l)$ gene of drosophila and are required during organogenesis and bone differentiation. It was shown that Dlx 5 is expressed in all the skeletal structures of mid-gestation mice embryos after first cartilage formation [111]. Additionally, it was reported that mice lacking Dlx5 expression display craniofacial defects, delayed ossification of the roof of the skull, and abnormal osteogenesis [112]. It is noteworthy that human miR-203, down-regulated in bone metastatic prostate cancer cells, binds to the 3'UTR of Dlx5 [54]. As Dlx5 is a well-known inducer of RUNX2 [113,114] and, therefore, an important regulator of osteogenesis [115], miR-203 represses RUNX2's expression by an additional indirect targeting, resulting in the blockade of osteoblastic differentiation (Figure 3). Interestingly, another study reported that bone-metastasis cells from prostate cancer also express RUNX2 [116]. Furthermore, it was here demonstrated that through its ability to target both RUNX2 and Dlx5, miR-203 decreases the expression of osteopontin and osteocalcin in prostate cancer cells. Such a decrease affects the osteo-mimetic features of these cells, normally allowing them to grow and develop in bones, and here suggesting the implication of this miRNA in the metastatic process [54].

Tricho-Rhino-Phalangeal Syndrome I (TRPS1)

The chondrogenic GATA-like transcription factor tricho-rhino-phalangeal syndrome I (TRPS1) is another key effector of skeletal development. Mutations of this gene are responsible for tricho-rhino-phalangeal syndrome, which notably includes skeletal abnormalities [117]. This gene is overexpressed in breast [118] and colon cancers [119]. This gene is also used as a biomarker in this model, as its expression level correlates with both the lymph node metastasis invasion and the pathological stage. Surprisingly, it was reported that this factor has the ability to directly bind to the OCN promoter to act as a repressor of its transcription [120]. A recent work reported that miR-34c targets TRPS1, resulting in the blockade of both osteoblastic and chondrogenic differentiation and further supporting the tumor-suppressing role of miR-34c (Figure 3) [96].

\section{4. p53-Related miRNAs Regulate Osteoblastic Differentiation by Targeting Pleiotropic Pathways}

\subsection{The p53-Related miRNAs' Interplay with the Notch, Wnt/ß-catenin, and Sonic/Hedgehog (HH) Pathways}

\subsubsection{The Notch Pathway}

The Notch pathway, a transmembrane receptor, with its roles in development and cell fate determination is of particular interest in the context of this review. Its role throughout the course of both osteoblastic differentiation and tumorigenesis remains unclear and it seems that it has a dual effect on those processes, depending on the differentiation stage and cell context. For instance, it was reported that activation of the Notch pathway in osteocytes induces suppression of bone resorption in cancellous bones and an increased bone formation in cortical bones [121]. It was also demonstrated that such effects were mediated by the induction of the expression of osteoprotegerin (OPG) and by the activation of the Wnt/ $\beta$-catenin pathway (Figure 4). These data were supported by Tezuka et al., 
who reported the early osteoblastic differentiation-promoting role of Notch1 in human primary bone marrow MSCs and its ability to stimulate calcified nodule formation in an MC3T3-E1 model [122]. In addition, HES-1 (Hairy/enhancer of split) and HEY-1 (Hes-related protein), two Notch-related genes, were reported to enhance the osteogenic differentiation of MSCs by cooperating with and inducing RUNX2's expression [123]. Contradicting this data, genetic experiments have shown that removal of Notch1 and Notch 2 from the early limb-mesenchyme of mice results in an increase in the trabecular bone mass of the animals, arguing in favor of an inhibitory role of such genes in osteoblastic differentiation [124]. In this work, investigators showed that this bone-phenotypic change was due to the Notch inhibitory effects on osteoblastic differentiation, at least as mediated by the HES and HEY proteins. In this case, the latter were found to directly interact with RUNX2 to consequently inhibit its transcriptional capabilities in both $\mathrm{CHO}$ and ST2 mouse bone stromal cells.

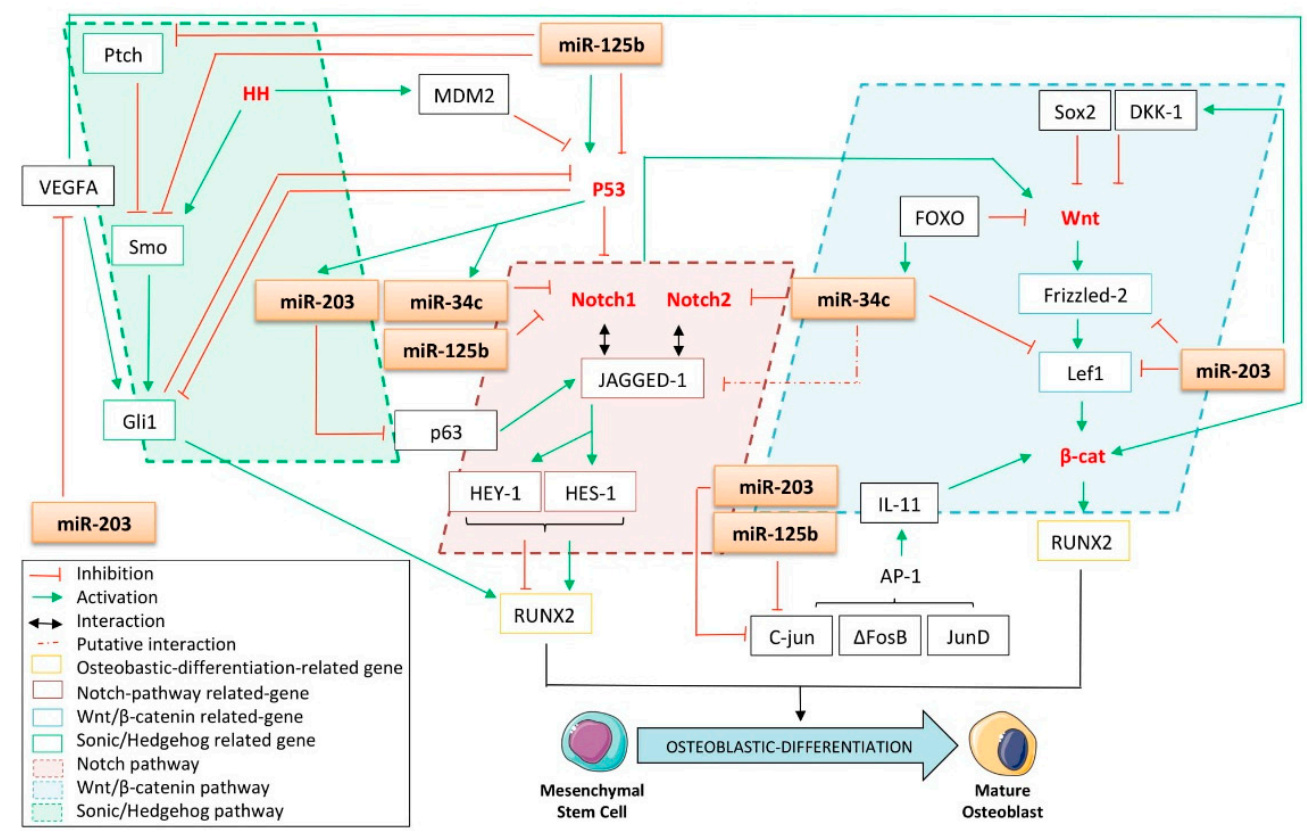

Figure 4. The p53-related miRNAs controls the osteoblastic differentiation through interplay with Notch, Wnt/ $\beta$-catenin, and Sonic/Hedgehog $(\mathrm{HH})$ pathways. AP-1: Activator protein- $1 ; \beta$-cat: $\beta$-catenin; DKK-1: Dickkopf Wnt signaling pathway inhibitor 1; FOXO: Forkhead transcription factor; HES-1: Hairy/enhancer f split; HEY-1: Hes-related protein; HH: Sonic/Hedgehog; IL: interleukin; Lef1: lymphoid enhancer-binding factor 1; MDM2: mouse double minute 2 homologue; RUNX2: runt-related transcription factor 2; Ptch: Patched receptor; Smo: Smoothened; VEGFA: Vascular endothelial growth factor A.

Furthermore, Notch signaling is often deregulated in cancers and, here, still has a dual role, as it supports either oncogenic or tumor suppressor functions, depending on the cancers [125]. Nonetheless, it seems that it favors osteosarcoma progression as an up-regulater of Notch itself. Up-regulation of JAGGED-1, HES-1, and HEY-2, three Notch target genes, and also the zinc finger transcription factor Osterix was reported in primary human osteosarcoma samples as compared to normal osteoblasts [126]. This data is enforced by the fact that Notch1, JAGGED-1, and Delta-like-1 were also found to be overexpressed in gliomas [127]. Regarding the effect of Notch signaling on osteoblastic differentiation and tumorigenesis, targeting this pathway could represent a relevant strategy toward cancer treatment, especially osteosarcoma. Additionally, Engin et al. showed an up-regulation of genes related to the Notch pathway in osteosarcoma samples developed in p53-heterozygous mice, suggesting that p53 is a Notch repressor in this context [126]. The multilevel crosstalk between both p53 and Notch pathways is well documented and occurs through reciprocal regulation of these two signaling factors [128]. Of note, 
the p53-inhibitory function on the Notch pathway described by Pastorcic et al. could be strengthened by the study of the p53-related miRNAs [129].

The putative targeting of Notch1 by miR-34c was first mentioned by Corney et al. and further confirmed by Bae's work, who not only experimentally demonstrated the direct interaction between these two partners but also reported miR-34c's inhibitory role throughout the course of the osteoblastic differentiation of bone marrow stromal cells $[45,130]$. Roy et al. also noticed a marked decrease in Notch1 protein expression consequent to the re-induction of miR-34c's expression after the treating of colon cancer cells with difluorinated curcumin [36]. More recently, $\mathrm{Xu}$ et al. confirmed the targeting of Notch1 by miR-34c in an osteosarcoma model and reported that the inhibition of this miRNA promotes the chemoresistance of the cells [131]. In addition, it was reported that the expression of miR-34c is up-regulated during mouse spermatogenesis, although the expression of Notch1 was shown to be down-regulated [132]. Furthermore, Manca et al. outlined the direct involvement of miR-125b in Notch1 down-regulation through its Notch1-mRNA 3'UTR targeting (Figure 4) [133]. Investigators have also shown that the overexpression of miR-125b in human primary keratinocytes leads to a significant decrease in Notch1 at the protein level. In addition, Notch2 was identified by Bouhallier et al. as being a direct target of miR-34c in the HeLa cervical cancer cell line [134]. Wu et al. further found that only miR-34c-3p was able to reduce Notch2 protein expression in glioblastoma cells, whereas miR-34c-5p did not [33]. Furthermore, in silico approaches in mice genetic models predict the presence of a potential binding site for miR-34c in the 3'UTR of JAGGED-1, one of the Notch's target genes, even if this has still not been experimentally validated [135]. Diao et al. recently reported that miR-203 indirectly impedes the Notch pathway through its targeting of the JAGGED-1-inducer p63 [56]. By introducing either miR-203 or a p63 siRNA into the RD rhabdomyosarcoma cell line, this group observed a reduction both in the JAGGED-1 transcript level and in HES-1 protein expression. Given the fact that both miR-125b and $-34 \mathrm{c}$ are found to be underexpressed in osteosarcomas [24,72], the reintroduction of these miRNAs could provide a promising strategy against the spread of this osteoblast-derived tumor through impairment of the Notch pathway.

\subsubsection{The Wnt Pathway}

The Wnt/ $\beta$-catenin pathway was also reported as being of paramount importance in the biology of bones. Rawadi et al. were among the first to suggest the involvement of this pathway in the regulation of osteoblastic differentiation, by highlighting that a Wnt autocrine loop leads to the induction of ALP expression and mediates the BMP-2-induced mineralization of pre-osteoblasts [136]. These results were further supported by Mansukhani et al., who correlated the Sox2-inhibitory role on the Wnt pathway and the inhibition of osteoblastic differentiation [137]. In line with these considerations, it is interesting to note that Thatcher et al. found that miR-203 directly targets lymphoid enhancer-binding factor 1 (Lef1), one of the Wnt pathway-related players in a zebrafish model (Figure 4) [138]. Interestingly, Xu et al. also found that this gene is a target of miR-34c in an osteosarcoma model [131]. Moreover, recent evidence suggests the targeting of the Wnt/ $\beta$-catenin-related receptor, Frizzled-2, by miR-203, even if no direct binding was attested [139]. In addition, it was found that miR-203 indirectly increases the expression of the Dickkopf Wnt signaling pathway inhibitor 1 (DKK-1), a secreted Wnt-related pathway inhibitor reported to impede osteogenesis in MSCs [140]. Interestingly, Lee et al. found that the expression of DKK-1 is increased in the sera of newly diagnosed osteosarcoma patients, suggesting the potential need to inhibit the $\mathrm{Wnt} / \beta$-catenin pathway at the onset of osteosarcoma carcinogenesis [141]. Finally, it is known that the Forkhead transcription factor FOXO suppresses the Wnt pathway and bone formation [142], while FOXO was also reported to induce the expression of miR-34c, highlighting, here, another miR-34c-related way to repress osteoblastic differentiation.

The transcription factors $\Delta$ FosB and JunD are two partners of the activator protein-1 (AP-1) complex and are both implicated in osteoblastic differentiation through an indirect regulatory mechanism allowing for the proper expression of RUNX2 [143]. It was demonstrated that the $\Delta \mathrm{FosB} / J u n D$ complex mediates the transcription of interleukin-11 (IL-11), itself able to activate the Wnt/ $\beta$-catenin pathway, 
rightly resulting in the induction of Runx2's expression. In addition, miR-125b was identified as targeting c-Jun, another member of the AP-1 complex, in its coding region and was also found to be critical in reducing the proliferative potential and migration capabilities of melanoma cells [73]. Furthermore, c-Jun was identified by Sonkoly et al., Tripathi et al., and Luo et al. as a direct target of miR-203 [53,144,145].

\subsubsection{The Sonic/Hedgehog (HH) Pathway}

The Sonic/Hedgehog $(\mathrm{HH})$ pathway is involved in many aspects of development, including the control of osteoblastic differentiation. It is now well established that its deregulation also sustains the growth of many human tumors. It is important to note that p53 is known to inhibit $\mathrm{HH}$ signaling, at least through regulation of Gli1, one of the effectors of the $\mathrm{HH}$ pathway. It was shown that p53 was able to reduce Gli1's expression level as well as its nuclear localization and activity [146]. In return, there is also a negative feedback loop exerted by $\mathrm{HH}$ on $\mathrm{p} 53$, as the same group demonstrated that Gli1 inhibits p53 (Figure 4) [146]. These data are strengthened by Abe et al., who demonstrated that $\mathrm{HH}$ induces the degradation of p53 by activating MDM2 [147]. It was found that miR-125b directly targets and functionally suppresses the seven-pass trans-membrane protein Smoothened (Smo), which rightly activates the Gli family of transcription factors [70]. Investigators have shown that the overexpression of miR-125b in medulloblastoma cells significantly reduces the mRNA levels of Gli1 and those of the Patched receptor (Ptch), both known as endogenous HH-related genes. In addition, the depletion of miR-125b increases Gli transcriptional activity, supporting the inhibitory role of this miRNA on the $\mathrm{HH}$ pathway (Figure 4). Vascular Endothelial Growth Factor A (VEGFA) is a growth factor implicated in the early stages of osteoblastic differentiation through its ability to stimulate the activity of the $\mathrm{HH}$ pathway and to increase the expression of $\beta$-catenin [148]. Interestingly, miR-203 was reported by Zhu et al. as targeting the VEGFA mRNA through its direct binding in a $3^{\prime}$ UTR seed sequence conserved across species (Figure 4) [60]. This group also reported an up-regulation of VEGFA levels in cervical cancer patients, which is inversely correlated with the expression of miR-203. In addition, the overexpression of miR-203 in this model markedly suppresses cell proliferation, tumor growth, and angiogenesis.

\subsection{The p53-Related miRNAs' Interplay with Bone Morphogenetic Proteins (BMP) and Transforming Growth Factor- $\beta$ (TGF- $\beta$ ) Pathways}

\subsubsection{The Bone Morphogenetic Proteins (BMP) Pathway}

Bone Morphogenetic proteins (BMPs) are members of the Transforming Growth Factor- $\beta$ (TGF- $\beta$ ) super-family of ligands and regulate various physiological processes including osteoblastic differentiation. BMPs are paracrine/autocrine local factors expressed by osteoblasts and they bind to two types of serine-threonine kinase receptors (BMPR-I and BMPR-II) to up-regulate RUNX2 expression during osteoblastic differentiation (Figure 5) [149]. The Smads proteins are the signaling effectors of both the BMP pathway and the canonical TGF- $\beta$ pathway. They are classified into three subgroups related to their structures and functions [150]: the pathway-restricted Smads (R-Smads), the common-mediator Smad (C-Smad), and the inhibitory Smads (I-Smads). Smad4 is the lone C-Smad and is consequently implicated in the connection between the BMP and the TGF- $\beta$ pathways. It is well-known that upon increase in the expression levels of the cyclin-inhibitors p21 ${ }^{\mathrm{CIP} 1}$ and p27 ${ }^{\mathrm{KIP} 1}$, BMP-4 induces a $\mathrm{G}_{0} / \mathrm{G}_{1}$ cell cycle arrest and enhances cell differentiation into osteoblast-like cells [151]. Thanks to their series of mice strains lacking one or several BMPs, Bandyopadhyay et al. showed that BMP2/BMP4-limb-deficient animals display critical defects in skeletal differentiation [152]. The distal femurs of mice that are one or three weeks of age do not show any bone marrow cavity, trabecular bone, or cortical bone as compared to their wild-type counterparts. This phenotype could be explained by the undifferentiated fibroblast-like osteoprogenitors found in the bone shaft of such mice, expressing normal amounts of Coll-I and RUNX2 but an insignificant amount of Osterix at three weeks. The work undertaken by these investigators reveals the particular role of BMP2 and BMP4 in the completion of osteogenesis. 


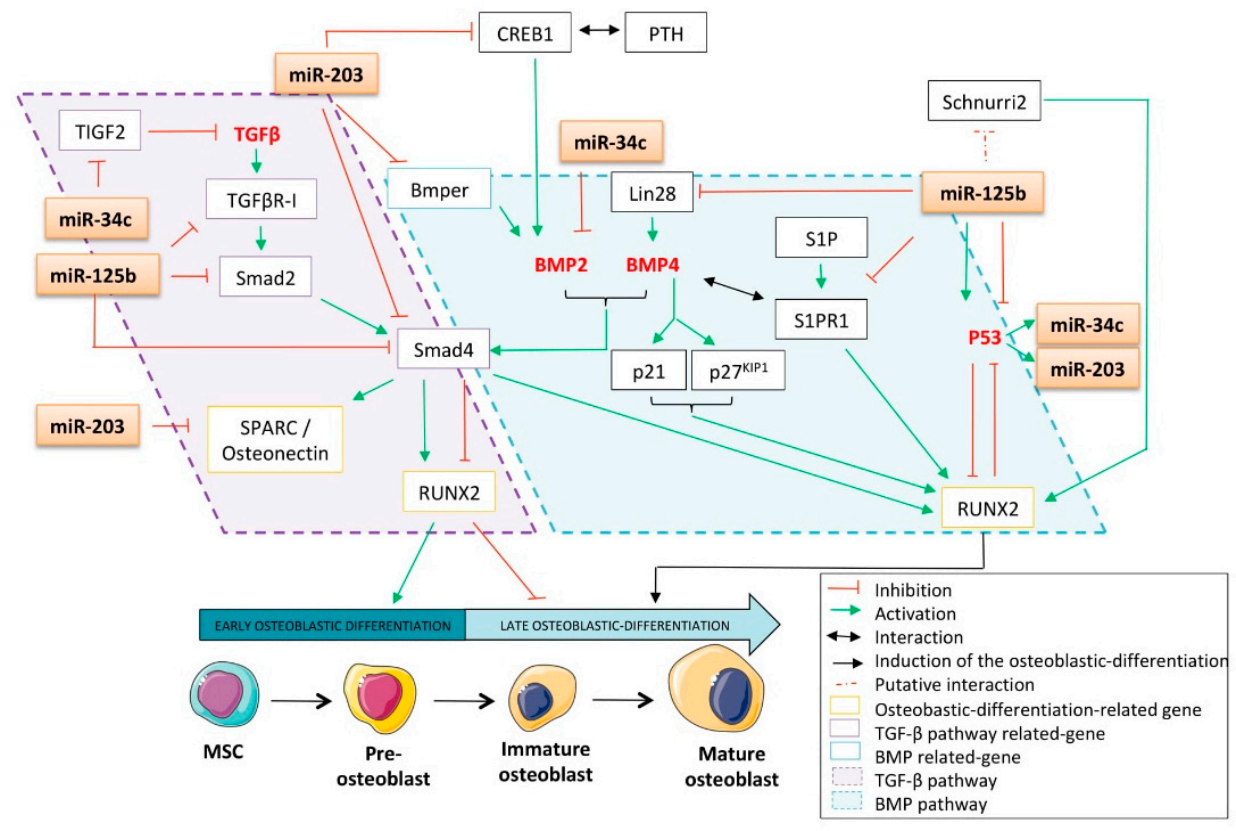

Figure 5. The p53-related miRNAs controls the osteoblastic differentiation through an interplay of both the bone morphogenetic protein (BMP) and the transforming growth factor $\beta$ (TGF- $\beta$ ) pathways. Bmper: BMP endothelial cell precursor derived regulator; BMP2: bone morphogenetic protein 2; BMP4: bone morphogenetic protein 4; CREB1: c-AMP responsive element binding protein 1; PTH: parathormone; RUNX2: runt-related transcription factor 2; SPARC: secreted protein acidic and rich in cystein; S1P: Sphingosine 1 phosphate; S1PR1: Sphingosine 1 phosphate receptor 1 ; TGF- $\beta$ : transforming growth factor $\beta$; TGF $\beta$ R-I: transforming growth factor $\beta$ geceptor I.

Fotinos et al. recently reported that miR-34c directly targets the 3'UTR of BMP-2 in a lung carcinoma model, in which this miRNA was found to be down-regulated [153]. Cao et al. reported that the secreted glycoprotein BMP endothelial cell precursor derived regulator (Bmper) is a target of miR-203 (Figure 5) [154]. As Bmper is implicated in the sustained activation of the BMP pathway [155,156], the miR-203-targeting of this protein sustains its role against osteoblastic differentiation. In addition, targeting Bmper probably testifies to the miR-203 anti-tumor role, as this protein was also shown to be overexpressed in human colon, lung, and cervix adenocarcinomas and promotes cellular proliferative, migratory, and invasive behavior [155]. In addition, Saini et al. reported that human miR-203 binds to the 3'UTR of the C-Smad Smad4 in their prostate cancer model [54]. As Smad4 is the lone C-Smad, it is also implicated in mediating the TGF- $\beta$ pathway, which was known to be involved in cancer progression and especially in the migratory features of malignant cells [157]. As a consequence, the targeting of Smad4 by miR-203 impairs both BMP and the TGF- $\beta$ pathways and can modulate osteoblastic differentiation and/or tumorigenesis.

c-AMP responsive element-binding protein 1 (CREB1) is a transcription factor studied mainly in the neuronal context. Even if its exact functions in bone biology are not well understood, it is able to promote the differentiation of primary mouse osteoblasts. It was reported that the association of PTH with CREB1 promotes BMP-2 signaling, itself leading to the maturation of osteoblasts [158]. Interestingly, as assessed by RT-qPCR, Western blotting, and luciferase reporter assay, CREB1 was identified as a direct target of miR-203 in a multiple myeloma model (Figure 5) [55]. Of note, this specific targeting was further confirmed by Noguchi et al. in canine and human melanoma cells [159]. BMP-2 and TGF- $\beta$ are able to modulate the expression of the secreted protein acidic and rich in cysteine matrix-associated protein (SPARC/osteonectin). It is interesting to note that this glycoprotein is a direct target of miR-203 [160] and that cell cultures from SPARC-- mice have a decreased number of osteoblasts associated with a decreased bone formation as compared to their wt counterparts [161]. It was recently described that sphingosine-1-phosphate receptors play a crucial role in osteoblastic differentiation, as S1P 
(sphingosine-1-phosphate) enhances both BMP-2-stimulated RUNX2 expression and the ALP activity of $\mathrm{C} 2 \mathrm{C} 12$ cells [162]. Interestingly, it was reported that miR-125b directly inhibits sphingosine-1-phosphate receptor 1 (S1PR1) in the placenta [163]. Another possible BMP-related mechanism explaining the effect of miR-125b on osteoblastic differentiation could be the fact that the stem cell factor lin-28 is another validated target of this miRNA (Figure 5) [164]. Indeed, Ma et al. recently found that lin-28 was an inducer of the expression of BMP-4 [165]; therefore, miR-125b-mediated lin-28 inhibition could result in a lower BMP-4 level than that required for proper osteoblastic differentiation. Zhang et al. corroborated these results by comparing the miRNA expression profile of human adipose-derived stem cells (hADSC) pre- and post-osteogenic induction [166]. They found that miR-125b is down-regulated after osteogenic differentiation, whereas the zinc-finger transcription factor Schnurri-2, a putative target of this miRNA directly related to bone remodeling, was overexpressed [167].

\subsubsection{The Transforming Growth Factor- $\beta$ (TGF- $\beta$ ) Pathway}

Transforming Growth Factor- $\beta$ (TGF- $\beta$ ) is a pleiotropic cytokine abundantly stored in bones. In mammals, it is found as three different isoforms: TGF- $\beta 1$, TGF- $\beta 2$, and TGF- $\beta 3$. This cytokine has been reported to have a dual role during both osteoblastic differentiation and tumorigenesis; it has been widely reported that it promotes the early phases of osteoblastic differentiation and represses the terminal phases [168]. As TGF- $\beta$ is reported to inhibit the expression of RUNX2 [169], it seems relevant that impairing the TGF- $\beta$ pathway may have a critical influence on osteoblastic differentiation. This hypothesis was recently verified by Rana et al., who observed that impairing the TGF- $\beta$ pathway through the use of an anti-TGF- $\beta$ antibody improves doxorubicin-mediated inhibition of osteoblastic differentiation and increases the frequency of osteoblast colony-forming units [170]. In addition, the anti-osteoblastic-differentiation role of the TGF- $\beta$ pathway was supported by Maeda et al. [171]. They demonstrated that the TGF $\beta$ R-I inhibitor SB431542 not only promotes bone nodule formation from C2C12 mouse myoblasts but also increases both BMP-4-induced BSP expression and the production of ALP from human MSCs. Furthermore, TIGF2 is an inhibitor of the TGF- $\beta$ pathway and was identified by Bouhallier et al. as being a direct target of miR-34c in a HeLa cervical cancer model [134]. MiR-34c-mediated TIGF2 inhibition could, thus, contribute to the activation of the TGF- $\beta$ pathway and consequently result in the inhibition of osteoblastic differentiation. In addition, it was reported that the transfection of miR-125b into leukemia cells leads to a significant reduction in the expression of Smad2, Smad4, and TGFßR-I at the protein level [172]. These results were further sustained by the study of Zhou et al., who demonstrated the direct binding of miR-125 to the 3'-UTR of Smad2 [173].

4.3. The p53-Related miRNAs' Interplay with Fibroblast Growth Factor (FGF), Epidermal Growth Factor (EGF), Janus Kinase/Signal Transducer and Activator of Transcription (JAK/STAT), C-jun N-Terminal Kinase/p38 (JNK/p38), the Mitogen-Activated Protein Kinase/ERK (MAPK/ERK) Pathway, and Other Kinase-Related Pathways

\subsubsection{The Fibroblast Growth Factor (FGF) Pathway}

Fibroblast growth factor (FGF)/FGFR signaling is another crucial pathway involved in skeletal development [174]. Previously, a giant-cell tumor model demonstrated that FGFR-2IIIc signaling is a potent enhancer of the osteogenic differentiation program [175]. In this study, the authors showed that the knocking down of the expression of FGFR2-IIIc by siRNAs in mesenchymal stromal cells of a giant-cell tumor of the bone leads to a significant decrease in the expression of the three osteoblastic differentiation markers ALP, OPN, and RUNX2. Additionally, FGFR2-IIIc ${ }^{-/-}$mice display delayed ossification during fetal development and dwarfism in the long bones and axial skeleton [176]. Moreover, a very recently published study reported that FGFR-1 is implicated in the proliferation of the MG63 osteosarcoma cell line, arguing for the inhibition of this pathway to potentially counteract the development of bone sarcomas [177]. It is, thus, interesting to correlate these data with the fact that miR-125b was shown to directly target FGFR-2 in a psoriasis model, suggesting another mechanism by which this miRNA could inhibit both osteoblastic differentiation and carcinogenesis 
(Figure 6) [75]. In addition, miR-203 was identified as being a direct inhibitor of FGF2 in renal cancer [178]. In accordance with these results, it was also highlighted that FGFR-2 promotes osteogenic differentiation through the serine/threonine kinase protein kinase $C$ alpha (PKC $\alpha$ ) and the ERK1/2 pathways in murine MSCs [179]. Interestingly, as miR-203 was validated as a bona fide direct regulator of PKC $\alpha$ in a lung cancer model (Figure 6) [180], the silencing of the expression of miR-34c was shown to activate PKC's expression at the protein level, suggesting that this miRNA has an inhibitory role on osteoblastic differentiation [181].

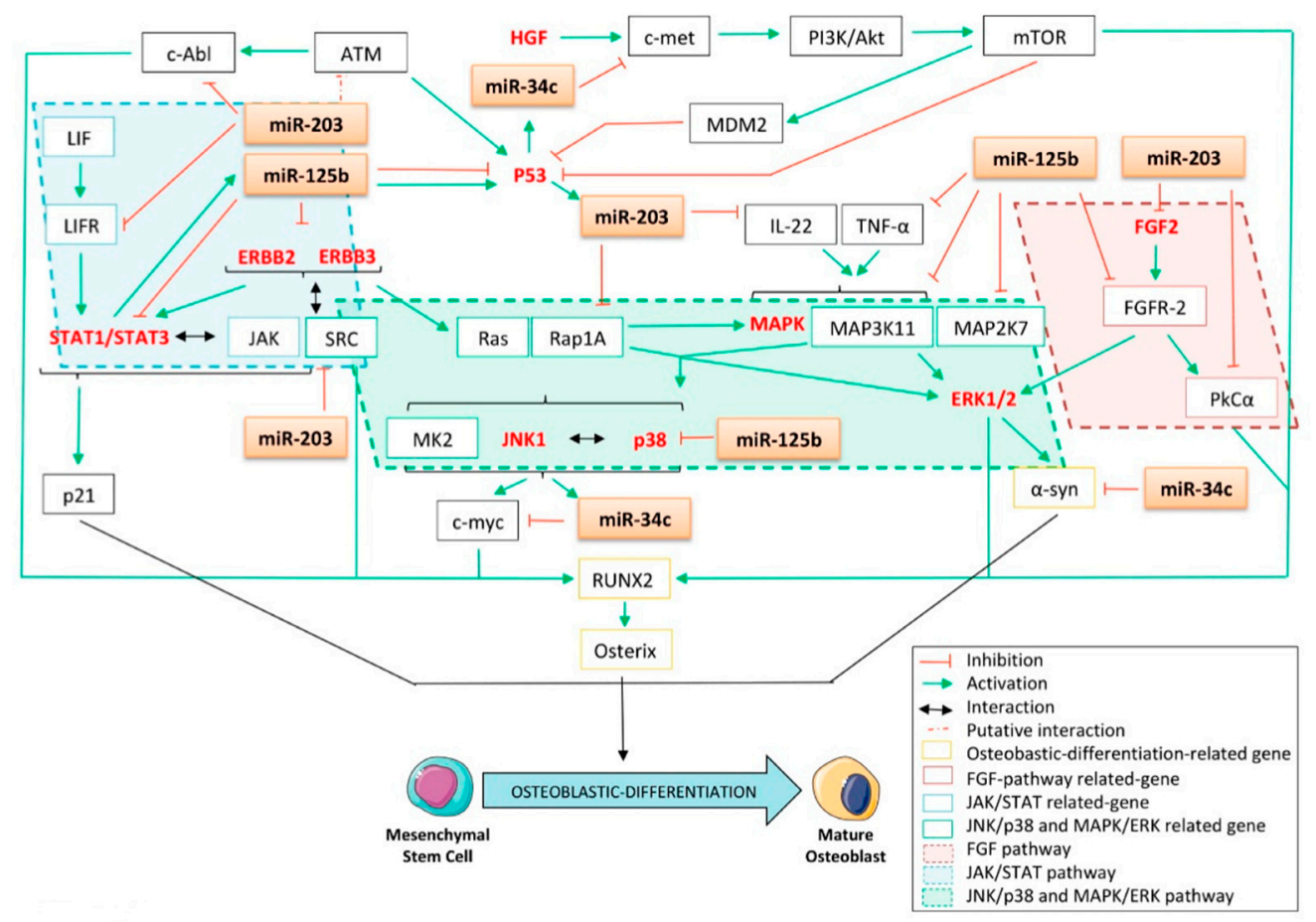

Figure 6. The p53-related miRNAs' interplay with the fibroblast growth factor (FGF), the epidermal growth factor (EGF), the Janus kinase/signal transducer and activator of transcription (JAK/STAT), the C-jun N-terminal kinase/p38 (JNK/p38), the mitogen-activated protein kinase/ERK (MAPK/ERK) pathway and the other kinases-related pathways. ATM: ataraxia telangiectasia mutated; $\alpha$-syn: $\alpha$-synuclein; EGF: epidermal growth factor; FGF: fibroblast growth factor; FGF2: fibroblast growth factor 2; FGFR: fibroblast growth factor receptor; FGFR-2: fibroblast growth factor receptor 2; IL-22: interleukin-22; HGF: hepatocyte growth factor; JAK: Janus kinase; JNK: C-jun N-terminal kinase; JNK1: C-jun N-terminal kinase 1; LIF: leukemia inhibitory factor; LIFR: leukemia inhibitory factor receptor; MAPK: mitogen-activated protein kinase; MAP2K7: mitogen-activated protein kinase kinase 7; MAP3K11: mitogen-activated protein kinase kinase kinase 11; MDM2: mouse double minute 2 homologue; mTOR: mammalian target of rapamycin; PI3K: phosphoinositide 3 kinase; PKC $\alpha$ : protein kinase C alpha; STAT: signal transducer and activator of transcription; STAT1: signal transducer and activator of transcription 1; STAT3: signal transducer and activator of transcription 3; RUNX2: runt-related transcription factor 2; TNF- $\alpha$ : tumor necrosis factor $\alpha$.

\subsubsection{The Epidermal Growth Factor (EGF) Pathway}

The implication of the epidermal growth factor receptor family member ERBB in periosteal osteoblastic differentiation was also reported [182]. In a bone-related cancer context, it was found that both the TC-71 and the SK-ES1 Ewing sarcoma cell lines overexpressed ERBB2 and that a blockade of this receptor led to increased sensitivity toward Taxol [183]. Furthermore, it was reported that miR-125b directly targets both ERBB2 and ERBB3 in SKBR3 breast cancer cells [184]. More recently, He et al. corroborated those results in ovarian cell lines stably overexpressing ERBB2 or ERBB3 lacking 3'UTR [74]. The results concerning ERBB2 were confirmed in umbilical vein endothelial cells [185], 
while the direct interaction between this mRNA and miR-125b was further confirmed in a small cell lung cancer model [186].

\subsubsection{The Janus Kinase/Signal Transducer and Activator of Transcription (JAK/STAT) Pathway}

By generating mice with osteoblasts in which the expression of the signal transducer and activator of transcription 3 (STAT3) is knocked down, Itoh et al. reported that, in vivo, STAT3 signaling plays a critical role in bone formation because of the osteopenic phenotype that the animals display [187]. In line with these results, it was further demonstrated that STAT3 signaling promotes in vitro MSC osteoblastic differentiation in osteogenic media [188]. Interestingly, Bellido et al. showed that the induction of p21 is elicited by the binding of STAT3 at its promoter sequence (Figure 6) [189]. Furthermore, the $\mathrm{G}_{0} / \mathrm{G}_{1}$ cell-cycle arrest, required for committed osteoblast cells, is mediated by the induction of p21 CIP1 in response to BMP4 [151]. In addition, siRNAs against p21 block OSM-induced ALP activity in the MG63 osteosarcoma cell line [189]. Together, this body of evidence suggests the role of p21 and STAT3 in osteoblastic differentiation and the proper function of osteoblast-derived cells. Thus, impairing STAT3 signaling through miRNA targeting could result in a decrease in osteoblastic differentiation.

The direct targeting of STAT3 by miR-125b was demonstrated by Liu et al. and could partially explain its inhibitory effect on osteoblastic differentiation (Figure 6) [72]. MiR-125b was found to be down-regulated in patients' osteosarcoma samples as compared to the corresponding non-cancerous samples as well as in the MG63, SaOS-2, and U2OS osteosarcoma cell lines [72]. Another group confirmed that STAT3 is a miR-125b's target by studying its implications during myelopoiesis [190]. In addition, as STAT3 is a well-known oncogene often overexpressed or activated in cancer [191], impairment in its expression could be a promising strategy toward cancer progression. By overexpressing miR-125b in the SaOS2 and MG-63 osteosarcoma cell lines, Liu et al. observed an in vitro decrease in cell growth and cell migration as well as delayed tumor growth in vivo [72]. Interestingly, this group has also shown that STAT3 is a transcriptional activator of the expression of miR-125b, highlighting a novel feedback loop regulation between STAT3 and miR-125b in osteosarcoma [72]. In addition, it is known that JAK1/STAT1/STAT3 signaling was activated through the binding of the leukemia inhibitory factor (LIF) to its receptor, LIFR. In this matter, it was demonstrated that the re-introduction of miR-203 into the RD and DH30 rhabdomyosarcoma cell lines leads to the subsequent inhibition of LIFR at the protein level (Figure 6) [56]. Furthermore, this group reports that, as a consequence of direct targeting of the LIFR transcript, miR-203 impairs proper JAK1/STAT1/STAT3 signaling activation. Together, these data could add a novel potential osteoblastic differentiation regulation mode through the p53/miR-203/STAT3 pathway.

\subsubsection{The C-jun N-Terminal Kinase/p38 (JNK/p38) and Mitogen-Activated Protein Kinase/ERK (MAPK/ERK) Pathways and Other Kinase-Related Pathways}

Through their phosphorylating capabilities, kinase proteins are involved in the activation and/or repression of almost all the signaling cascades. This paragraph will focus on the clear evidence arguing for the interplay between p53-related miRNAs and such kinases, reinforcing the role of miRNAs as small inhibitors of osteoblastic differentiation. It is established that BMP-2-induced osteoblastic differentiation depends on both C-Jun N-terminal kinase (JNK) and p38 mitogen-activated protein kinase activation [192]. It was further clarified that such a differentiation process is sustained by the small G-protein Rap1A, through its ability to phosphorylate both ERK and p38, thus resulting in the activation of these pathways [193]. Interestingly, miR-125b was shown to directly target the $3^{\prime}$ UTR of p38 [194] while miR-203 was reported to directly target the $3^{\prime}$ UTR of Rap1A, adding here two other mechanisms by which these miRNAs reduce osteoblastic differentiation (Figure 6) [195]. In addition, it was recently demonstrated that the c-Myc proto-oncogene is a downstream target of JNK1 [196] as well as a proper inducer of osteogenesis, as its overexpression was reported to promote the BMP-2-induced osteoblastic differentiation of human MSCs [197]. Moreover, Cannell et al. reported that etoposide-induced DNA damage led to a significant down-regulation of c-Myc as well as the induction of the expression of 
miR-34c [198]. These authors correlated the results to miR-34c's ability to directly target the c-Myc $3^{\prime}$ UTR (Figure 6). Interestingly, they also found that the DNA-damage-mediated induction of miR-34c still occurred in SaOS2 osteosarcoma cells devoid of a functional p53, highlighting here an alternative p53-independent pathway involving p38/MAPK/MK2 leading to miR-34c transcription. Nonetheless, the interplay between the kinase pathways is complex, as mitogen-activated protein kinase kinase kinase 11 (MAP3K11) not only was reported to directly activate p38 but was also recently suggested to be miR-125b's target in early B-cells [199]. Additionally, Xu et al. reported that the overexpression of miR-125b in the UT-SCC-7 cutaneous squamous carcinoma cell line consequently down-regulates the expression of mitogen-activated protein kinase kinase 7 (MAP2K7), leading to the inhibition of the G1/S transition and reducing both cellular proliferation and clonogenicity [71].

In line with these results, it was also shown that expression of the $\alpha$-synuclein ( $\alpha$-syn) protein depends on the activation of the ERK1/2 pathway [200]. This protein further helps stimulate the differentiation of osteosarcoma cells, as its overexpression in the MG63 cell line leads to a significant increase in ALP activity as well as increased ALP and OCN expression [201]. Interestingly, miR-34c was reported to directly target the $3^{\prime}$ UTR of the $\alpha$-syn mRNA in human neuroblast cells (Figure 6) [202]. Similarly, the c-Abl tyrosine-kinase was also reported to be implicated in osteoblastic differentiation, as osteoblasts from stromal and calvarial explants isolated from $\mathrm{Abl}^{-/-}$mice displayed a reduced expression of ALP and OCN associated with diminished mineral-deposition capabilities [203]. In line with this consideration, miR-203 was suggested to target c- $\mathrm{Abl}$, as the protein expression level of the latter is inflected by an ectopic modulation of the expression of this miRNA [204]. In addition, it was shown that the kinase capabilities of the SRC protein implicated it in osteoblastic differentiation, as it helps stabilize Osterix, consequently increasing the transcriptional activity of this factor [205]. Interestingly, Wang et al. showed that miR-203 directly targets SRC in a lung cancer model (Figure 6) [206]. It was reported that the DNA-repair-associated Ser/Thr kinase Ataraxia telangiectasia mutated (ATM) is involved in osteoblastic differentiation, as it positively regulates the expression of Osterix [207]. Interestingly, a high expression of miR-203 was found to be significantly associated with a low expression of ATM in sporadic breast carcinomas [208].

Another interesting mechanism is worthy of attention here and concerns the reported synergistic effects of both the tumor necrosis factor alpha (TNF- $\alpha$ ) and Interleukin-22 (IL-22) in inducing the phosphorylation of the MAPKs, p38, and ERK1/2 proteins in keratinocytes, thus resulting in the activation of those pathways [209]. Interestingly, in our bone-related concerns, Wang et al. reported the dual role of TNF- $\alpha$ throughout the course of the osteogenic differentiation of bone marrow MSCs [210]. Their study argues in favor of the promoting effect of this factor during the early phases of differentiation, while it seems to have an inhibitory role during the more advanced stages. The ability of miR-125b to directly bind to the TNF- $\alpha-3^{\prime}$ UTR seems to correlate with its inhibitory effects on osteoblastic differentiation during the early stages of the process (Figure 6) [211]. In addition, even if ILs are a class of molecules implicated mainly in the immune response, they are also able to act on non-immune cells, thus sustaining several biological mechanisms such as differentiation. In particular, IL-22 was shown to promote the expression of some osteoblast-related markers such as RUNX2, MSX2, and OCN in cells from periodontal ligaments and to sustain the formation of mineralized nodules [212]. In this context, it is of particular interest that miR-203 directly inhibits the IL-22 mRNA (Figure 6) [213].

Finally, it was reported that enforcing the expression of the tyrosine kinase receptor c-met into primary cultures of human bone-derived cells converts them into osteosarcoma cells and leads to an increase in the expression of several osteoblastic differentiation markers such as RUNX2 and Osterix [214]. In addition, c-met was identified by Cai et al. as a direct target of miR-34c in a laryngeal carcinoma model (Figure 6) [30]. Investigators showed that increasing miR-34c's expression in Hep-2 cells inhibits both proliferation and migrative capabilities as well as induces apoptosis. In addition, such c-met targeting was further confirmed in both gastric cancer [37] and uveal melanoma [32]. It was also reported, in this model, that miR-34c consequently impacts the p-Akt level in a hepatocyte growth factor (HGF)-dependent manner, further resulting in the inhibition of both the proliferative and migrative 
capabilities of the cells. In addition, Moumen et al. found that c-met enhances Phosphoinositide 3 kinase/Akt (PI3K/Akt) signaling, thus resulting in the activation of mammalian target of rapamycin (mTOR) [215]. As the latter exerts both a direct and an indirect inhibition of p53 through MDM2 activation, such a mechanism could explain the feedback-regulation loop between p53 and miR-34c.

\subsection{The p53-Related miRNAs' Interplay between Oxidative Stress, the Nuclear Factor-kappa $b$ (NF- $k b$ ) Pathway, and Osteoblastic Differentiation}

It was previously reported that $\mathrm{H}_{2} \mathrm{O}_{2}$ stress down-regulates the expression of the osteogenic markers ALP, BSP, and RUNX2, further resulting in the inhibition of osteoblastic differentiation of the MC3T3-E1 calvarial mouse osteoblast's precursor cells [216]. These results are sustained by another study, in which osteoblasts treated with hydrogen peroxide, a reactive oxygen species (ROS)-generating agent, displayed a reduced expression of RUNX2 [217]. It was also demonstrated that oxidative stress inhibits osteoblastic differentiation via activation of the nuclear factor-kappa $b(\mathrm{NF}-\mathrm{kb})$ pathways [218]. Interestingly, the same study reported that NF- $k b$ induces the transcription of miR-125b (Figure 7). These data corroborate the work of Manca et al., who found that hydrogen-peroxide-induced oxidative stress up-regulates miR-125b in HaCat keratinocytes [133]. In addition, it is interesting to note that the expression of $\mathrm{miR}-125 \mathrm{~b}$ is sustained by the oxidative-stress-related transcription factor nuclear factor (erythroid-derived 2)-like 2 (NRF2) [219], which is rightly reported to impede osteoblastic differentiation through its inhibitory capabilities toward RUNX2-dependent transcriptional activity [220]. Furthermore, another control loop sustains the expression of miR-125b itself, thanks to its direct targeting capabilities towards NF- kb inhibitor interacting Ras-like 2 (NKIRAS2) [221], an NF- $k b$ repressor [222]. It is also interesting to note that B-cell lymphoma/leukemia 3 (BCL3), which is a member of the NFkb-inhibitory complex Inhibitor of NF-kb (Ikb) [223], is another direct target of miR-125b (Figure 7) [224]. Thus, through those mechanisms, miR-125b still contributes to activating the NF-kb pathway, leading to the inhibition of osteoblastic differentiation. Intriguingly, contradictory data reports that NF-kb promotes the osteoblastic differentiation of human stromal cells derived from adipose tissue (hADSC) through induction of the transcriptional co-activator Tafazzin (TAZ) [225]. It was also demonstrated that miR-125b directly targets TAZ in hepatocellular carcinoma cells, suggesting another way by which this miRNA fine-tunes the maturation of the osteoblasts [226]. In line with this consideration, it was reported that the stem cell factor (SCF) protects the osteoblasts from oxidative stress [227] and that this factor is a direct target of miR-34c (Figure 7) [228].

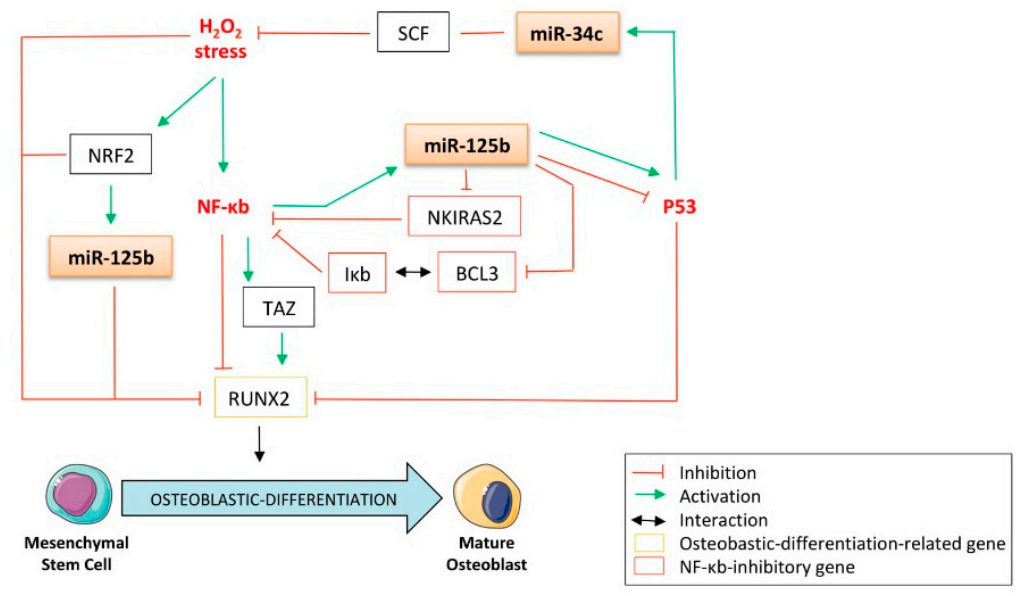

Figure 7. The p53-related miRNAs' interplay between oxidative-stress, the nuclear factor-kappa b (NF-kb) pathway, and osteoblastic differentiation. BCL3: B-cell leukemia/lymphoma 3; Ikb: inhibitor of NF-kb; NKIRAS2: NF-kb Inhibitor interacting Ras-like 2; NF-kb: nuclear factor-kappa b; NRF2: nuclear factor (erythroid-derived 2)-like 2; RUNX2: runt-related transcription factor 2; SCF: stem cell factor; TAZ: tafazzin. 


\section{The p53-Related miRNAs' Interplay between the Epithelial-to-Mesenchymal Transition (EMT) and Osteoblastic Differentiation:}

The epithelial-to-mesenchymal transition (EMT) process is characterized by the loss of the epithelial features of the cancer cells, consequently triggering their mobility and spread throughout the body from the primary site in vivo. As the role of RUNX2 in osteoblastic differentiation and the osteogenic features of the bone-related cells is beyond any doubt, its implication in EMT was also reported [229]. The authors have shown that the siRNA-mediated silencing of this gene led to a significant down-regulation of the EMT markers Slug, Twist1, and matrix metalloproteinase 2 (MMP-2) in thyroid carcinoma cells. Bmi-1 is another important player in the chromatin-modulator polycomb complex involved in the promotion of the EMT process [230] and is often overexpressed in cancers. Its deregulation can partially explain some tumorigenic features of bone sarcomas, as it promotes both the in vitro anchorage-independent growth of Ewing sarcoma cells and their in vivo tumorigenicity [231]. It is further implicated in osteoblastic differentiation, as neonatal Bmi-1/- mice display skeletal growth retardation [232]. In addition, the expression of RUNX2 was reduced in the bone marrow MSCs from Bmi-1/- mice, which also exhibited decreased ALP activity. Wellner et al. were the first to report that the overexpression of miR-203 leads to Bmi-1-repression in a pancreatic carcinoma model due to its direct targeting of $3^{\prime}$ UTR (Figure 8) [233]. These results were further confirmed by Saini et al. in a bone-metastatic prostate cancer model, in which the expression of miR-203 is attenuated [54]. In addition, Wu et al. recently showed that osteosarcoma cells overexpressing Bmi-1 are more prone to resist cisplatin through increased activation of the PI3K/Akt pathway and to display higher proliferative and migrative capabilities both in vitro and in vivo [234]. Furthermore, Yin et al. found that miR-203-mediated inhibition of Bmi-1 sensitizes breast cancer cells to 5-fluorouracil [235]. It was also found that re-expression of this miRNA in bone-metastatic prostate cancer cells induces the mesenchymal-to-epithelial transition (MET) characterized by increased E-cadherin expression and the down-regulation of the mesenchymal markers vimentin and fibronectin [54]. The functional consequences reported by the authors are the suppression of invasiveness and cell motility in vitro and a reduction in the metastatic potential in vivo, arguing in favor of the tumor-suppressive role of miR-203. Additionally, the E-box-binding transcriptional repressor ZEB2, a well-known E-cadherin-regulator and inducer of EMT [236], was found to be a direct target of miR-203 [54]. In turn, it was demonstrated that ZEB1 has a transcriptional inhibitory role toward miR-203 through its direct binding at its promoter region [233], suggesting a feedback loop between the ZEB family proteins and miR-203 (Figure 8). Slug is another interesting gene in the context of this review because of its implication in both the EMT process and the functioning of osteoblasts. Its expression was found to be correlated to the expressions of RUNX2, OPN, OCN, Coll-I, and the Wnt/ $\beta$-catenin signaling in osteoblasts [237]. Interestingly, miR-203 was shown to be a bona fide inhibitor of this gene through its direct-targeting properties, as evidenced in a gastric carcinoma model (Figure 8) [238]. Given the metastatic spreading concerns of pathology, it is also important to note that $\mathrm{Xu}$ et al. reported the tumor-suppressive role of miR-125b through its ability to suppress the motility and invasive capabilities of cutaneous squamous carcinoma cells [71]. Their microarray and RT-qPCR analysis revealed that the overexpression of this miRNA in the UT-SCC-7 cutaneous squamous carcinoma cell line consequently down-regulates the expression of two matrix metalloproteinases (MMP):,MMP-7 and MMP-13, with the latter being further demonstrated as a direct target of miR-125b. This targeting was confirmed in a bladder cancer model [239]. In light of all this evidence, the p53-related miRNAs studied here display an interesting EMT-inhibitory role linked to their negative impact on osteoblastic differentiation. 


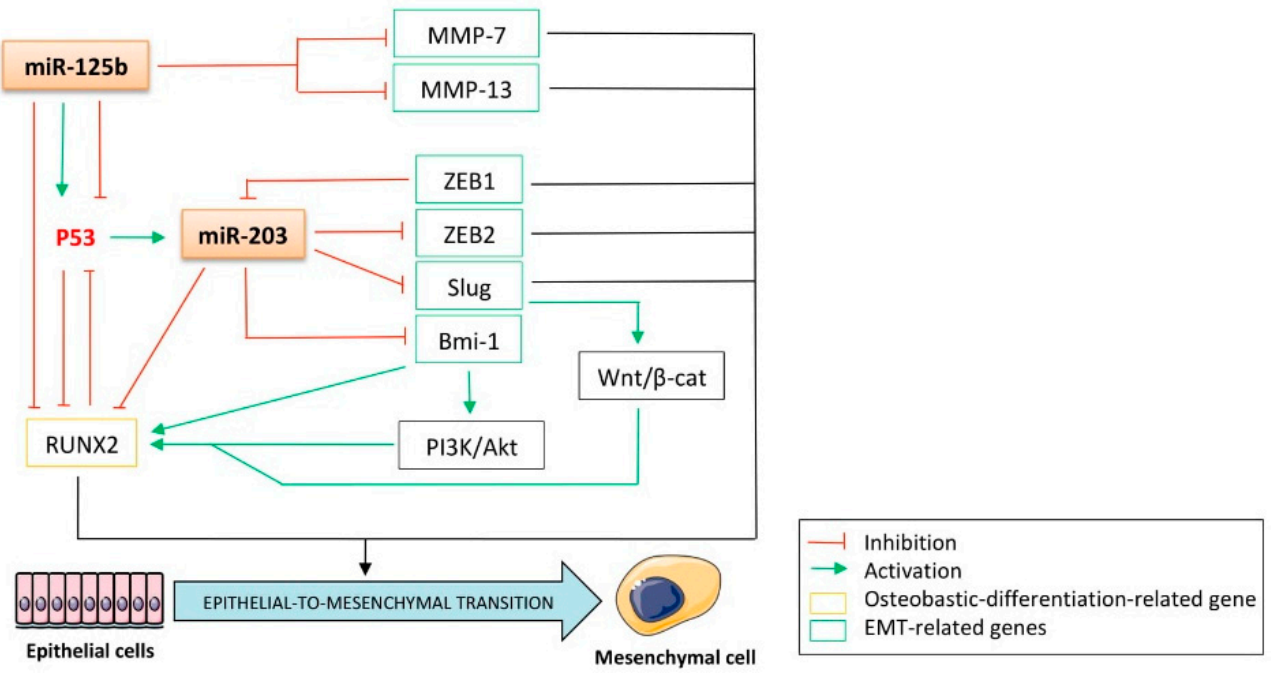

Figure 8. The p53-related miRNAs' interplay between the epithelial-to-mesenchymal transition (EMT) and the osteoblastic-differentiation. $\beta$-cat: $\beta$-catenin; EMT: epithelial-to-mesenchymal transition; MMP: matrix metalloproteinase; MMP-7: matrix metalloproteinase 7; MMP-13: matrix metalloproteinase 13; PI3K: phosphoinositide 3 kinase; RUNX2: runt-related transcription factor 2.

\section{The p53-Related miRNAs' Control of the Cell Cycle and Apoptosis is Linked to Their Role as Osteoblastic-Differentiation Regulators}

Regarding the amount of the aforementioned targets of miR-34c, $-125 b$, and -203 involved in pathways directly or indirectly controlling osteoblastic differentiation, plenty of evidence has been highlighted of the implication of these miRNAs in the regulation of osteogenesis processes. Nonetheless, in controlling the cell proliferation rate and the apoptotic mechanisms, their tumor-suppressor role is of paramount interest in both a tumorigenicity context and a cellular-differentiation context. Interestingly, it was shown that the addition of calcium ions and vitamin D3 to the culture media of human alveolar bone explants promotes the expression of the small inhibitor of apoptosis (IAP) survivin/BIRC5 as well as several osteoblastic markers such as ALP and OCN, suggesting the implication of this gene in the maturation of osteoblasts [240]. By directly interacting with survivin, miR-203 was reported to inhibit the proliferation and induce the apoptosis of prostate cancer cells (Figure 9) [54]. The same targeting was further supported in a bladder cancer model [241]. Interestingly, ChIP assays in a prostate cancer model reveal that RUNX2 regulates survivin expression through its direct binding at consensus sequences in the survivin promoter [242]. Ji et al. reported the direct targeting of the anti-apoptotic factor B-cell CLL/Lymphoma 2 (Bcl-2) by miR-34c in the gastric cancer cell line Kato III [243]. Furthermore, ectopic transfections of this miRNA in the PC3 prostate cancer cell line lead to a significant reduction of the expression of Bcl-2 and E2F3 at the protein level, indicating that this miRNA also reduces the S-phase's cell number [34]. It is also important to note that ChIP experiments and reporter assays reveal that RUNX2 was a direct inducer of Bcl-2 expression through its promoter-binding capabilities [244]. Furthermore, Nagase et al. demonstrated that the biological functions of the osteoblasts of $\mathrm{Bcl}^{-{ }^{--}}$mice were altered, thus highlighting the role of this gene in promoting the proper differentiation, activity, and survival of such a cell type [245]. 


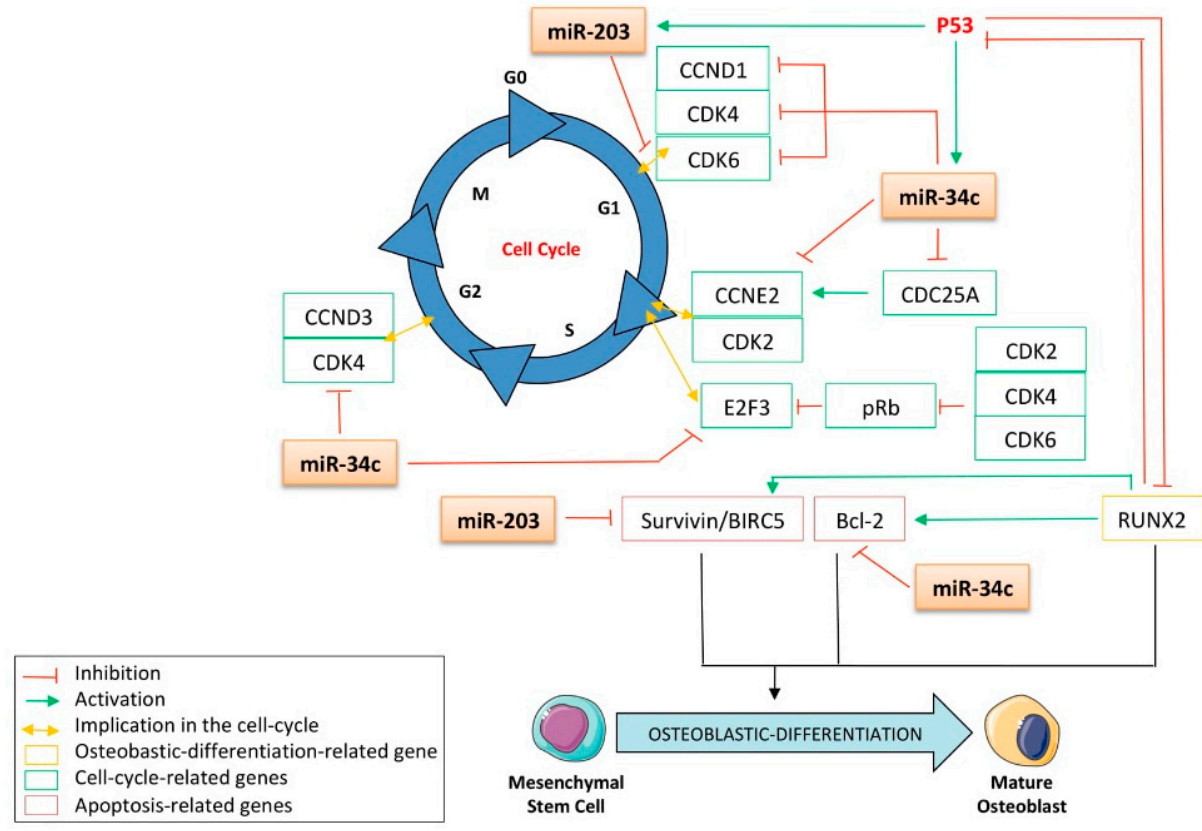

Figure 9. The p53-related miRNAs' control of the cell cycle and apoptosis is linked to the role as osteoblastic-differentiation regulators. CCN: cyclin; CCND1: cyclin D1; CCND3: cyclin D3; CCNE2: cyclin E2; CDC25A: cell division cycle 25A; CDK: cyclin-dependent kinase; CDK2: cyclin-dependent kinase 2; CDK4: cyclin-dependent kinase 4; CDK6: cyclin-dependent kinase 6; Bcl-2: B-cell CLL/Lymphoma 2; RUNX2: runt-related transcription factor 2.

Several publications have described the implication of the p53-related miRNAs in cyclin/cyclin-dependent kinase (CDK) regulation, thus resulting in a cell cycle blockade. The control of this process by these miRNAs is of particular interest, as it not only contributes to the death of the cancer cells but also leads to the inhibition of osteoblastic differentiation. For instance, ectopic transfections of miR-34c were reported to inhibit the growth of gastric cancer cells through suppression of the expression of cyclin-dependent kinase 4 (CDK4) and cyclin E2 (CCNE2) even if no direct interaction was demonstrated between the miRNA and these mRNAs (Figure 9) [37]. Wei et al. further confirmed that the same miRNA decreases the CDK4 and CDK6 levels in osteoblasts [97], while Dong et al. verified these results in uveal melanoma cells [32]. In addition, miR-34c was reported to directly target cyclin D1 (CCND1), thus helping to inhibit the proliferation of osteoblasts [97]. Similarly, the expression of CDK6 was consequently reduced to a miR-203 ectopic expression in both esophageal [246] and ovarian cancers [247]. In line with these data, it was also recently reported that the siRNA-mediated knockdown of cell division cycle 25A (CDC25A) inhibits the osteoblastic differentiation of hMSCs [248]. In addition, $\mathrm{miR}-34 \mathrm{c}$ was found to reduce the protein expression of CDC25A even if no direct interaction between this miRNA and the CDC25A mRNA was evidenced (Figure 9) [247].

\section{Conclusions}

Taken together, the results of all these studies validate or strengthen the notion that these miRNAs support p53's counteracting activity against both osteoblastic differentiation and tumorigenesis. Such features are attributable to the huge variety of pathways in which their direct or indirect targets are involved, all contributing to the inhibition of the expression of RUNX2, an osteoblastic-differentiation-related gene regulating the very early steps of the differentiation process. Thus, as the p53-related miRNAs interfere with Notch, Wnt/ $\beta$-cat, Sonic/Hedgehog (Figure 4), TGF- $\beta$, and BMP pathways (Figure 5), they have multiple ways to fine-tune the osteoblast-associated functions. Additionally, because they target pathways implicated in the control of proliferation, apoptosis, and cellular adaptation to the environment, such as the JAK/STAT, JNK/p38, and MAPK/ERK pathways (Figure 6), these miRNAs are obviously master regulators of tumorigenesis. Two of the 
p53-regulated miRs studied in this review have already been identified in bone or bone sarcomas (Table 1). Furthermore, as the different targets of these miRNAs is evidenced in both cancerous and non-cancerous models (Table S1), the universality of their action mode is highlighted here and might suggest that they could act together in our bone-related concerns. The various expression levels of these molecules during the course of the osteoblastic differentiation reveal that their target genes are necessarily subjected to a thin temporal control and remind us that the cellular fate is highly dependent of external signals. In the context of metabolic-bone pathologies, such as osteoporosis or osteopetrosis in which osteoblastic differentiation is deregulated, these miRNAs could provide interesting therapeutic options. In cancer-related concerns, it seems that these miRNAs control the pathways implicated in oxidative stress to which the cancer cells are subjected during the tumor-growth process (Figure 7), as well as the EMT, which allows them to further disseminate into the body (Figure 8). Finally, these miRNAs are also implicated in cell-cycle regulation in which p53 plays a major role (Figure 9). However, as p53 is often mutated in osteosarcoma and in Ewing sarcoma, it seems obvious that alternative pathways lead to the expression of these miRNAs and promote their anti-tumor role in the absence of this factor. Collectively, these data construct a novel glimpse at the role of these miRNAs as promising targets for improving bone-associated disease treatments, especially in osteosarcomas, which combine defects in both the osteoblastic-differentiation program and in the control of normal cellular behavior. 
Table 1. p53-related miRNAs and the nature of the interaction with their target genes in bone development and sarcomas.

\begin{tabular}{|c|c|c|c|c|c|c|c|}
\hline \multicolumn{5}{|c|}{ Characterisation of the Interaction } & \multicolumn{3}{|c|}{ Reference } \\
\hline miRNA & p53's Link & Target Gene & $\begin{array}{c}\text { Nature of the } \\
\text { Targeting }\end{array}$ & Model & Authors & $\begin{array}{c}\text { Date of } \\
\text { Publication }\end{array}$ & Journal \\
\hline \multirow{5}{*}{$\operatorname{miR}-125 b$} & conflicting data: & $\mathrm{CBF} \beta$ & direct 3'UTR & Mesenchymal stem cells & Huang et al., & 2014 & Biochimie \\
\hline & activator of p53's & p53 & direct 3'UTR & Ewing Sarcoma & Ida et al., & 2013 & Cancer Cell Int. \\
\hline & expression \& & STAT3 & direct 3'UTR & Osteosarcoma & Liu et al., & 2011 & Biochem Biophys Res Commun \\
\hline & repressor of p53's & CCND1 & direct 3'UTR & Mouse osteoblasts & Wei et al., & 2012 & J Cell Biol. \\
\hline & expression & CDK4 & no direct 3'UTR & Mouse osteoblasts & Wei et al., & 2012 & J Cell Biol. \\
\hline \multirow{7}{*}{$\operatorname{miR}-34 \mathrm{c}$} & & CDK6 & no direct 3'UTR & Mouse osteoblasts & Wei et al., & 2012 & J Cell Biol. \\
\hline & directly induced & Lef1 & direct 3’UTR & Osteosarcoma & Xu et al., & 2014 & Med Oncol. \\
\hline & by p53 & Notch1 & direct 3'UTR & Osteosarcoma & Xu et al., & 2014 & Med Oncol. \\
\hline & & RUNX2 & direct 3'UTR & Mouse osteoblasts & Zhang et al., & 2012 & J Biol Chem. \\
\hline & & Kणतละ & direct 3'UTR & Osteosarcoma & $\begin{array}{c}\text { Van der Deen et } \\
\text { al., }\end{array}$ & 2013 & J Biol Chem. \\
\hline & & SATB2 & direct 3'UTR & Mouse osteoblasts & Wei et al., & 2012 & J Cell Biol. \\
\hline & & TRPS1 & direct 3'UTR & Mouse osteoblasts & Zhang et al., & 2012 & J Biol Chem. \\
\hline
\end{tabular}


Supplementary Materials: The following are available online at http://www.mdpi.com/2073-4409/9/4/810/s1, Table S1: The p53-related miRNAs and the nature of the interaction with their target genes.

Funding: This research was funded by "Fondation ARC”, “La ligue contre le Cancer", SFCE, ANR, Région Pays de la loire, Cancéropôle Grand Ouest.

Acknowledgments: Thank you for the financial support from "Fondation ARC", "La ligue contre le Cancer", SFCE, ANR, Région Pays de la loire. We also thank Cancéropôle Grand Ouest for supporting the "Niches and Epigenetics of Tumors" network, http://www.canceropole-grandouest.com.

Conflicts of Interest: The authors declare no conflicts of interest.

\section{References}

1. Geller, D.S.; Gorlick, R. Osteosarcoma: A review of diagnosis, management, and treatment strategies. Clin. Adv. Hematol. Oncol. 2010, 8, 705-718.

2. Marina, N.; Gebhardt, M.; Teot, L.; Gorlick, R. Biology and therapeutic advances for pediatric osteosarcoma. Oncologist 2004, 9, 422-441. [CrossRef] [PubMed]

3. Mutsaers, A.J.; Walkley, C.R. Cells of origin in osteosarcoma: Mesenchymal stem cells or osteoblast committed cells? Bone 2014, 62, 56-63. [CrossRef]

4. Wadayama, B.; Toguchida, J.; Shimizu, T.; Ishizaki, K.; Sasaki, M.S.; Kotoura, Y.; Yamamuro, T. Mutation spectrum of the retinoblastoma gene in osteosarcomas. Cancer Res. 1994, 54, 3042-3048. [PubMed]

5. Sandberg, A.A.; Bridge, J.A. Updates on the cytogenetics and molecular genetics of bone and soft tissue tumors: Osteosarcoma and related tumors. Cancer Genet. Cytogenet. 2003, 145, 1-30. [CrossRef]

6. Mohseny, A.B.; Szuhai, K.; Romeo, S.; Buddingh, E.P.; Briaire-de Bruijn, I.; de Jong, D.; van Pel, M.; Cleton-Jansen, A.M.; Hogendoorn, P.C. Osteosarcoma originates from mesenchymal stem cells in consequence of aneuploidization and genomic loss of Cdkn2. J. Pathol. 2009, 219, 294-305. [CrossRef] [PubMed]

7. Lee, R.C.; Feinbaum, R.L.; Ambros, V. The C. elegans heterochronic gene lin-4 encodes small RNAs with antisense complementarity to lin-14. Cell 1993, 75, 843-854. [CrossRef]

8. Bartel, D.P. MicroRNAs: Target recognition and regulatory functions. Cell 2009, 136, 215-233. [CrossRef]

9. Lewis, B.P.; Burge, C.B.; Bartel, D.P. Conserved seed pairing, often flanked by adenosines, indicates that thousands of human genes are microRNA targets. Cell 2005, 120, 15-20. [CrossRef]

10. Calin, G.A.; Dumitru, C.D.; Shimizu, M.; Bichi, R.; Zupo, S.; Noch, E.; Aldler, H.; Rattan, S.; Keating, M.; Rai, K.; et al. Frequent deletions and down-regulation of micro- RNA genes miR15 and miR16 at 13q14 in chronic lymphocytic leukemia. Proc. Natl. Acad. Sci. USA 2002, 99, 15524-15529. [CrossRef]

11. Vousden, K.H.; Lu, X. Live or let die: The cell's response to p53. Nat. Rev. Cancer 2002, 2, 594-604. [CrossRef] [PubMed]

12. Oren, M. Decision making by p53: Life, death and cancer. Cell Death Differ. 2003, 10, 431-442. [CrossRef] [PubMed]

13. Hollstein, M.; Sidransky, D.; Vogelstein, B.; Harris, C.C. p53 mutations in human cancers. Science 1991, 253, 49-53. [CrossRef] [PubMed]

14. Levine, A.J.; Hu, W.; Feng, Z. The P53 pathway: What questions remain to be explored? Cell Death Differ. 2006, 13, 1027-1036. [CrossRef]

15. Lang, G.A.; Iwakuma, T.; Suh, Y.A.; Liu, G.; Rao, V.A.; Parant, J.M.; Valentin-Vega, Y.A.; Terzian, T.; Caldwell, L.C.; Strong, L.C.; et al. Gain of function of a p53 hot spot mutation in a mouse model of Li-Fraumeni syndrome. Cell 2004, 119, 861-872. [CrossRef]

16. Olive, K.P.; Tuveson, D.A.; Ruhe, Z.C.; Yin, B.; Willis, N.A.; Bronson, R.T.; Crowley, D.; Jacks, T. Mutant p53 gain of function in two mouse models of Li-Fraumeni syndrome. Cell 2004, 119, 847-860. [CrossRef]

17. Vogelstein, B.; Lane, D.; Levine, A.J. Surfing the p53 network. Nature 2000, 408, 307-310. [CrossRef]

18. Tyner, S.D.; Venkatachalam, S.; Choi, J.; Jones, S.; Ghebranious, N.; Igelmann, H.; Lu, X.; Soron, G.; Cooper, B.; Brayton, C.; et al. p53 mutant mice that display early ageing-associated phenotypes. Nature 2002, 415, 45-53. [CrossRef]

19. Zambetti, G.P.; Horwitz, E.M.; Schipani, E. Skeletons in the p53 tumor suppressor closet: Genetic evidence that p53 blocks bone differentiation and development. J. Cell Biol. 2006, 172, 795-797. [CrossRef] 
20. Wang, X.; Kua, H.Y.; Hu, Y.; Guo, K.; Zeng, Q.; Wu, Q.; Ng,H.H.; Karsenty, G.; de Crombrugghe, B.; Yeh, J.; et al. p53 functions as a negative regulator of osteoblastogenesis, osteoblast-dependent osteoclastogenesis, and bone remodeling. J. Cell Biol. 2006, 172, 115-125. [CrossRef]

21. Nakashima, K.; Zhou, X.; Kunkel, G.; Zhang, Z.; Deng, J.M.; Behringer, R.R.; de Crombrugghe, B. The novel zinc finger-containing transcription factor osterix is required for osteoblast differentiation and bone formation. Cell 2002, 108, 17-29. [CrossRef]

22. Lengner, C.J.; Steinman, H.A.; Gagnon, J.; Smith, T.W.; Henderson, J.E.; Kream, B.E.; Stein, G.S.; Lian, J.B.; Jones, S.N. Osteoblast differentiation and skeletal development are regulated by Mdm2-p53 signaling. J. Cell Biol. 2006, 172, 909-921. [CrossRef]

23. Molchadsky, A.; Shats, I.; Goldfinger, N.; Pevsner-Fischer, M.; Olson, M.; Rinon, A.; Tzahor, E.; Lozano, G.; Zipori, D.; Sarig, R.; et al. p53 plays a role in mesenchymal differentiation programs, in a cell fate dependent manner. PLos ONE 2008, 3, e3707. [CrossRef] [PubMed]

24. van der Deen, M.; Taipaleenmaki, H.; Zhang, Y.; Teplyuk, N.M.; Gupta, A.; Cinghu, S.; Shogren, K.; Maran, A.; Yaszemski, M.J.; Ling, L.; et al. MicroRNA-34c inversely couples the biological functions of the runt-related transcription factor RUNX2 and the tumor suppressor p53 in osteosarcoma. J. Biol. Chem. 2013, 288, 21307-21319. [CrossRef] [PubMed]

25. Ozaki, T.; Wu, D.; Sugimoto, H.; Nagase, H.; Nakagawara, A. Runt-related transcription factor 2 (RUNX2) inhibits p53-dependent apoptosis through the collaboration with HDAC6 in response to DNA damage. Cell Death Dis. 2013, 4, e610. [CrossRef]

26. Eskildsen, T.; Taipaleenmaki, H.; Stenvang, J.; Abdallah, B.M.; Ditzel, N.; Nossent, A.Y.; Bak, M.; Kauppinen, S.; Kassem, M. MicroRNA-138 regulates osteogenic differentiation of human stromal (mesenchymal) stem cells in vivo. Proc. Natl. Acad. Sci. USA 2011, 108, 6139-6144. [CrossRef]

27. Inose, H.; Ochi, H.; Kimura, A.; Fujita, K.; Xu, R.; Sato, S.; Iwasaki, M.; Sunamura, S.; Takeuchi, Y.; Fukumoto, S.; et al. A microRNA regulatory mechanism of osteoblast differentiation. Proc. Natl. Acad. Sci. USA 2009, 106, 20794-20799. [CrossRef]

28. Hermeking, H. The miR-34 family in cancer and apoptosis. Cell Death Differ. 2010, 17, 193-199. [CrossRef]

29. Li, T.; Chen, J.X.; Fu, X.P.; Yang, S.; Zhang, Z.; Chen Kh, H.; Li, Y. microRNA expression profiling of nasopharyngeal carcinoma. Oncol. Rep. 2011, 25, 1353-1363. [CrossRef]

30. Cai, K.M.; Bao, X.L.; Kong, X.H.; Jinag, W.; Mao, M.R.; Chu, J.S.; Huang, Y.J.; Zhao, X.J. Hsa-miR-34c suppresses growth and invasion of human laryngeal carcinoma cells via targeting c-Met. Int. J. Mol. Med. 2010, 25, 565-571. [CrossRef]

31. Schetter, A.J.; Leung, S.Y.; Sohn, J.J.; Zanetti, K.A.; Bowman, E.D.; Yanaihara, N.; Yuen, S.T.; Chan, T.L.; Kwong, D.L.; Au, G.K.; et al. MicroRNA expression profiles associated with prognosis and therapeutic outcome in colon adenocarcinoma. Jama J. Am. Med. Assoc. 2008, 299, 425-436. [CrossRef] [PubMed]

32. Dong, F.; Lou, D. MicroRNA-34b/c suppresses uveal melanoma cell proliferation and migration through multiple targets. Mol. Vis. 2012, 18,537-546. [PubMed]

33. Wu, Z.; Wu, Y.; Tian, Y.; Sun, X.; Liu, J.; Ren, H.; Liang, C.; Song, L.; Hu, H.; Wang, L.; et al. Differential effects of miR-34c-3p and miR-34c-5p on the proliferation, apoptosis and invasion of glioma cells. Oncol. Lett. 2013, 6, 1447-1452. [CrossRef] [PubMed]

34. Hagman, Z.; Larne, O.; Edsjo, A.; Bjartell, A.; Ehrnstrom, R.A.; Ulmert, D.; Lilja, H.; Ceder, Y. miR-34c is downregulated in prostate cancer and exerts tumor suppressive functions. Int. J. Cancer. J. Int. Du Cancer 2010, 127, 2768-2776. [CrossRef] [PubMed]

35. Toyota, M.; Suzuki, H.; Sasaki, Y.; Maruyama, R.; Imai, K.; Shinomura, Y.; Tokino, T. Epigenetic silencing of microRNA-34b/c and B-cell translocation gene 4 is associated with CpG island methylation in colorectal cancer. Cancer Res. 2008, 68, 4123-4132. [CrossRef]

36. Roy, S.; Levi, E.; Majumdar, A.P.; Sarkar, F.H. Expression of miR-34 is lost in colon cancer which can be re-expressed by a novel agent CDF. J. Hematol. Oncol. 2012, 5, 58. [CrossRef]

37. Suzuki, H.; Yamamoto, E.; Nojima, M.; Kai, M.; Yamano, H.O.; Yoshikawa, K.; Kimura, T.; Kudo, T.; Harada, E.; Sugai, T.; et al. Methylation-associated silencing of microRNA-34b/c in gastric cancer and its involvement in an epigenetic field defect. Carcinogenesis 2010, 31, 2066-2073. [CrossRef]

38. Chim, C.S.; Wan, T.S.; Wong, K.Y.; Fung, T.K.; Drexler, H.G.; Wong, K.F. Methylation of miR-34a, miR-34b/c, miR-124-1 and miR-203 in Ph-negative myeloproliferative neoplasms. J. Transl. Med. 2011, 9, 197. [CrossRef] 
39. Wang, Z.; Chen, Z.; Gao, Y.; Li, N.; Li, B.; Tan, F.; Tan, X.; Lu, N.; Sun, Y.; Sun, J.; et al. DNA hypermethylation of microRNA-34b/c has prognostic value for stage non-small cell lung cancer. Cancer Biol. Ther. 2011, 11, 490-496. [CrossRef]

40. Wong, T.S.; Liu, X.B.; Wong, B.Y.; Ng, R.W.; Yuen, A.P.; Wei, W.I. Mature miR-184 as Potential Oncogenic microRNA of Squamous Cell Carcinoma of Tongue. Clin. Cancer Res. Off. J. Am. Assoc. Cancer Res. 2008, 14, 2588-2592. [CrossRef]

41. Cheung, T.H.; Man, K.N.; Yu, M.Y.; Yim, S.F.; Siu, N.S.; Lo, K.W.; Doran, G.; Wong, R.R.; Wang, V.W.; Smith, D.I.; et al. Dysregulated microRNAs in the pathogenesis and progression of cervical neoplasm. Cell Cycle 2012, 11, 2876-2884. [CrossRef] [PubMed]

42. Li, R.; Qian, N.; Tao, K.; You, N.; Wang, X.; Dou, K. MicroRNAs involved in neoplastic transformation of liver cancer stem cells. J. Exp. Clin. Cancer Res. Cr 2010, 29, 169. [CrossRef] [PubMed]

43. He, L.; He, X.; Lim, L.P.; de Stanchina, E.; Xuan, Z.; Liang, Y.; Xue, W.; Zender, L.; Magnus, J.; Ridzon, D.; et al. A microRNA component of the p53 tumour suppressor network. Nature 2007, 447, 1130-1134. [CrossRef] [PubMed]

44. Bommer, G.T.; Gerin, I.; Feng, Y.; Kaczorowski, A.J.; Kuick, R.; Love, R.E.; Zhai, Y.; Giordano, T.J.; Qin, Z.S.; Moore, B.B.; et al. p53-mediated activation of miRNA34 candidate tumor-suppressor genes. Curr. Biol. $\mathrm{Cb}$ 2007, 17, 1298-1307. [CrossRef]

45. Corney, D.C.; Flesken-Nikitin, A.; Godwin, A.K.; Wang, W.; Nikitin, A.Y. MicroRNA-34b and MicroRNA-34c are targets of p53 and cooperate in control of cell proliferation and adhesion-independent growth. Cancer Res. 2007, 67, 8433-8438. [CrossRef]

46. Kumamoto, K.; Spillare, E.A.; Fujita, K.; Horikawa, I.; Yamashita, T.; Appella, E.; Nagashima, M.; Takenoshita, S.; Yokota, J.; Harris, C.C. Nutlin-3a activates p53 to both down-regulate inhibitor of growth 2 and up-regulate mir-34a, mir-34b, and mir-34c expression, and induce senescence. Cancer Res. 2008, 68, 3193-3203. [CrossRef]

47. He, C.; Xiong, J.; Xu, X.; Lu, W.; Liu, L.; Xiao, D.; Wang, D. Functional elucidation of MiR-34 in osteosarcoma cells and primary tumor samples. Biochem. Biophys. Res. Commun. 2009, 388, 35-40. [CrossRef]

48. Fabbri, M.; Bottoni, A.; Shimizu, M.; Spizzo, R.; Nicoloso, M.S.; Rossi, S.; Barbarotto, E.; Cimmino, A.; Adair, B.; Wojcik, S.E.; et al. Association of a microRNA/TP53 feedback circuitry with pathogenesis and outcome of B-cell chronic lymphocytic leukemia. Jama J. Am. Med. Assoc. 2011, 305, 59-67. [CrossRef]

49. Antonini, D.; Russo, M.T.; De Rosa, L.; Gorrese, M.; Del Vecchio, L.; Missero, C. Transcriptional repression of miR-34 family contributes to p63-mediated cell cycle progression in epidermal cells. J. Investig. Dermatol. 2010, 130, 1249-1257. [CrossRef]

50. Zhang, F.; Yang, Z.; Cao, M.; Xu, Y.; Li, J.; Chen, X.; Gao, Z.; Xin, J.; Zhou, S.; Zhou, Z.; et al. MiR-203 suppresses tumor growth and invasion and down-regulates MiR-21 expression through repressing Ran in esophageal cancer. Cancer Lett. 2013. [CrossRef]

51. Feber, A.; Xi, L.; Luketich, J.D.; Pennathur, A.; Landreneau, R.J.; Wu, M.; Swanson, S.J.; Godfrey, T.E.; Litle, V.R. MicroRNA expression profiles of esophageal cancer. J. Thorac. Cardiovasc. Surg. 2008, 135, 255-260, discussion 260. [CrossRef] [PubMed]

52. Kozubek, J.; Ma, Z.; Fleming, E.; Duggan, T.; Wu, R.; Shin, D.G.; Dadras, S.S. In-Depth Characterization of microRNA Transcriptome in Melanoma. PLos ONE 2013, 8, e72699. [CrossRef] [PubMed]

53. Sonkoly, E.; Loven, J.; Xu, N.; Meisgen, F.; Wei, T.; Brodin, P.; Jaks, V.; Kasper, M.; Shimokawa, T.; Harada, M.; et al. MicroRNA-203 functions as a tumor suppressor in basal cell carcinoma. Oncogenesis 2012, 1, e3. [CrossRef] [PubMed]

54. Saini, S.; Majid, S.; Yamamura, S.; Tabatabai, L.; Suh, S.O.; Shahryari, V.; Chen, Y.; Deng, G.; Tanaka, Y.; Dahiya, R. Regulatory Role of mir-203 in Prostate Cancer Progression and Metastasis. Clin. Cancer Res. Off. J. Am. Assoc. Cancer Res. 2011, 17, 5287-5298. [CrossRef]

55. Wong, K.Y.; Liang, R.; So, C.C.; Jin, D.Y.; Costello, J.F.; Chim, C.S. Epigenetic silencing of MIR203 in multiple myeloma. Br. J. Haematol. 2011, 154, 569-578. [CrossRef]

56. Diao, Y.; Guo, X.; Jiang, L.; Wang, G.; Zhang, C.; Wan, J.; Jin, Y.; Wu, Z. miR-203, a tumor suppressor frequently down-regulated by promoter hypermethylation in rhabdomyosarcoma. J. Biol. Chem. 2014, 289, 529-539. [CrossRef] 
57. Furuta, M.; Kozaki, K.I.; Tanaka, S.; Arii, S.; Imoto, I.; Inazawa, J. miR-124 and miR-203 are epigenetically silenced tumor-suppressive microRNAs in hepatocellular carcinoma. Carcinogenesis 2010, 31, 766-776. [CrossRef]

58. Kozaki, K.; Imoto, I.; Mogi, S.; Omura, K.; Inazawa, J. Exploration of tumor-suppressive microRNAs silenced by DNA hypermethylation in oral cancer. Cancer Res. 2008, 68, 2094-2105. [CrossRef]

59. Viticchie, G.; Lena, A.M.; Latina, A.; Formosa, A.; Gregersen, L.H.; Lund, A.H.; Bernardini, S.; Mauriello, A.; Miano, R.; Spagnoli, L.G.; et al. MiR-203 controls proliferation, migration and invasive potential of prostate cancer cell lines. Cell Cycle 2011, 10, 1121-1131. [CrossRef]

60. Zhu, X.; Er, K.; Mao, C.; Yan, Q.; Xu, H.; Zhang, Y.; Zhu, J.; Cui, F.; Zhao, W.; Shi, H. miR-203 suppresses tumor growth and angiogenesis by targeting VEGFA in cervical cancer. Cell. Physiol. Biochem. Int. J. Exp. Cell. Physiol. Biochem. Pharmacol. 2013, 32, 64-73. [CrossRef]

61. Zhang, J.; Zhou, Y.; Wu, Y.J.; Li, M.J.; Wang, R.J.; Huang, S.Q.; Gao, R.R.; Ma, L.; Shi, H.J. Hyper-methylated miR-203 dysregulates ABL1 and contributes to the nickel-induced tumorigenesis. Toxicol. Lett. 2013, 223, 42-51. [CrossRef]

62. Bueno, M.J.; Perez de Castro, I.; Gomez de Cedron, M.; Santos, J.; Calin, G.A.; Cigudosa, J.C.; Croce, C.M.; Fernandez-Piqueras, J.; Malumbres, M. Genetic and epigenetic silencing of microRNA-203 enhances ABL1 and BCR-ABL1 oncogene expression. Cancer Cell 2008, 13, 496-506. [CrossRef]

63. Gottardo, F.; Liu, C.G.; Ferracin, M.; Calin, G.A.; Fassan, M.; Bassi, P.; Sevignani, C.; Byrne, D.; Negrini, M.; Pagano, F.; et al. Micro-RNA profiling in kidney and bladder cancers. Urol. Oncol. 2007, 25, 387-392. [CrossRef]

64. Yi, R.; Poy, M.N.; Stoffel, M.; Fuchs, E. A skin microRNA promotes differentiation by repressing 'stemness'. Nature 2008, 452, 225-229. [CrossRef]

65. Suzuki, H.I.; Yamagata, K.; Sugimoto, K.; Iwamoto, T.; Kato, S.; Miyazono, K. Modulation of microRNA processing by p53. Nature 2009, 460, 529-533. [CrossRef] [PubMed]

66. McKenna, D.J.; McDade, S.S.; Patel, D.; McCance, D.J. MicroRNA 203 expression in keratinocytes is dependent on regulation of p53 levels by E6. J. Virol. 2010, 84, 10644-10652. [CrossRef] [PubMed]

67. Lena, A.M.; Shalom-Feuerstein, R.; Rivetti di Val Cervo, P.; Aberdam, D.; Knight, R.A.; Melino, G.; Candi, E. miR-203 represses 'stemness' by repressing DeltaNp63. Cell Death Differ. 2008, 15, 1187-1195. [CrossRef] [PubMed]

68. Chang, J.; Davis-Dusenbery, B.N.; Kashima, R.; Jiang, X.; Marathe, N.; Sessa, R.; Louie, J.; Gu, W.; Lagna, G.; Hata, A. Acetylation of p53 stimulates miRNA processing and determines cell survival following genotoxic stress. Embo J. 2013, 32, 3192-3205. [CrossRef] [PubMed]

69. Brosh, R.; Shalgi, R.; Liran, A.; Landan, G.; Korotayev, K.; Nguyen, G.H.; Enerly, E.; Johnsen, H.; Buganim, Y.; Solomon, H.; et al. p53-Repressed miRNAs are involved with E2F in a feed-forward loop promoting proliferation. Mol. Syst. Biol. 2008, 4, 229. [CrossRef]

70. Ferretti, E.; De Smaele, E.; Miele, E.; Laneve, P.; Po, A.; Pelloni, M.; Paganelli, A.; Di Marcotullio, L.; Caffarelli, E.; Screpanti, I.; et al. Concerted microRNA control of Hedgehog signalling in cerebellar neuronal progenitor and tumour cells. Embo J. 2008, 27, 2616-2627. [CrossRef]

71. Xu, N.; Zhang, L.; Meisgen, F.; Harada, M.; Heilborn, J.; Homey, B.; Grander, D.; Stahle, M.; Sonkoly, E.; Pivarcsi, A. MicroRNA-125b down-regulates matrix metallopeptidase 13 and inhibits cutaneous squamous cell carcinoma cell proliferation, migration, and invasion. J. Biol. Chem. 2012, 287, 29899-29908. [CrossRef] [PubMed]

72. Liu, L.H.; Li, H.; Li, J.P.; Zhong, H.; Zhang, H.C.; Chen, J.; Xiao, T. miR-125b suppresses the proliferation and migration of osteosarcoma cells through down-regulation of STAT3. Biochem. Biophys. Res. Commun. 2011, 416, 31-38. [CrossRef] [PubMed]

73. Kappelmann, M.; Kuphal, S.; Meister, G.; Vardimon, L.; Bosserhoff, A.K. MicroRNA miR-125b controls melanoma progression by direct regulation of c-Jun protein expression. Oncogene 2013, 32, 2984-2991. [CrossRef] [PubMed]

74. He, J.; Jing, Y.; Li, W.; Qian, X.; Xu, Q.; Li, F.S.; Liu, L.Z.; Jiang, B.H.; Jiang, Y. Roles and mechanism of miR-199a and miR-125b in tumor angiogenesis. PLoS ONE 2013, 8, e56647. [CrossRef]

75. Xu, N.; Brodin, P.; Wei, T.; Meisgen, F.; Eidsmo, L.; Nagy, N.; Kemeny, L.; Stahle, M.; Sonkoly, E.; Pivarcsi, A. MiR-125b, a microRNA downregulated in psoriasis, modulates keratinocyte proliferation by targeting FGFR2. J. Investig. Dermatol. 2011, 131, 1521-1529. [CrossRef] 
76. O'Connell, R.M.; Chaudhuri, A.A.; Rao, D.S.; Gibson, W.S.; Balazs, A.B.; Baltimore, D. MicroRNAs enriched in hematopoietic stem cells differentially regulate long-term hematopoietic output. Proc. Natl. Acad. Sci. USA 2010, 107, 14235-14240. [CrossRef]

77. Iida, K.; Fukushi, J.; Matsumoto, Y.; Oda, Y.; Takahashi, Y.; Fujiwara, T.; Fujiwara-Okada, Y.; Hatano, M.; Nabashima, A.; Kamura, S.; et al. miR-125b develops chemoresistance in Ewing sarcoma/primitive neuroectodermal tumor. Cancer Cell Int. 2013, 13, 21. [CrossRef]

78. Pinto, M.T.; Nicolete, L.D.; Rodrigues, E.S.; Palma, P.V.; Orellana, M.D.; Kashima, S.; Covas, D.T. Overexpression of hsa-miR-125b during osteoblastic differentiation does not influence levels of Runx2, osteopontin, and ALPL gene expression. Braz. J. Med. Biol. Res. = Rev. Bras. De Pesqui. Med. E Biol./Soc. Bras. De Biofisica ... [Et Al.] 2013, 46, 676-680. [CrossRef]

79. Inoue, K.; Fry, E.A. Alterations of p63 and p73 in human cancers. Subcell. Biochem. 2014, 85, 17-40. [CrossRef]

80. Toledo, F.; Wahl, G.M. Regulating the p53 pathway: In vitro hypotheses, in vivo veritas. Nat. Rev. Cancer 2006, 6, 909-923. [CrossRef]

81. Le, M.T.; Teh, C.; Shyh-Chang, N.; Xie, H.; Zhou, B.; Korzh, V.; Lodish, H.F.; Lim, B. MicroRNA-125b is a novel negative regulator of p53. Genes Dev. 2009, 23, 862-876. [CrossRef] [PubMed]

82. Amir, S.; Ma, A.H.; Shi, X.B.; Xue, L.; Kung, H.J.; Devere White, R.W. Oncomir miR-125b suppresses p14(ARF) to modulate p53-dependent and p53-independent apoptosis in prostate cancer. PLoS ONE 2013, 8, e61064. [CrossRef] [PubMed]

83. Nyholm, A.M.; Lerche, C.M.; Manfe, V.; Biskup, E.; Johansen, P.; Morling, N.; Thomsen, B.M.; Glud, M.; Gniadecki, R. miR-125b induces cellular senescence in malignant melanoma. Bmc Derm. 2014, $14,8$. [CrossRef] [PubMed]

84. Li, H.; Xie, H.; Liu, W.; Hu, R.; Huang, B.; Tan, Y.F.; Xu, K.; Sheng, Z.F.; Zhou, H.D.; Wu, X.P.; et al. A novel microRNA targeting HDAC5 regulates osteoblast differentiation in mice and contributes to primary osteoporosis in humans. J. Clin. Investig. 2009, 119, 3666-3677. [CrossRef] [PubMed]

85. Jones, K.B.; Salah, Z.; Del Mare, S.; Galasso, M.; Gaudio, E.; Nuovo, G.J.; Lovat, F.; LeBlanc, K.; Palatini, J.; Randall, R.L.; et al. miRNA signatures associate with pathogenesis and progression of osteosarcoma. Cancer Res. 2012, 72, 1865-1877. [CrossRef] [PubMed]

86. Zhang, Y.; Khan, D.; Delling, J.; Tobiasch, E. Mechanisms underlying the osteo- and adipo-differentiation of human mesenchymal stem cells. TheScientificWorldJournal 2012, 2012, 793823. [CrossRef]

87. Xiao, G.; Jiang, D.; Ge, C.; Zhao, Z.; Lai, Y.; Boules, H.; Phimphilai, M.; Yang, X.; Karsenty, G.; Franceschi, R.T. Cooperative interactions between activating transcription factor 4 and Runx2/Cbfa1 stimulate osteoblast-specific osteocalcin gene expression. J. Biol. Chem. 2005, 280, 30689-30696. [CrossRef]

88. Kania, M.A.; Bonner, A.S.; Duffy, J.B.; Gergen, J.P. The Drosophila segmentation gene runt encodes a novel nuclear regulatory protein that is also expressed in the developing nervous system. Genes Dev. 1990, 4, 1701-1713. [CrossRef]

89. Ito, Y. RUNX genes in development and cancer: Regulation of viral gene expression and the discovery of RUNX family genes. Adv. Cancer Res. 2008, 99, 33-76. [CrossRef]

90. Otto, F.; Thornell, A.P.; Crompton, T.; Denzel, A.; Gilmour, K.C.; Rosewell, I.R.; Stamp, G.W.; Beddington, R.S.; Mundlos, S.; Olsen, B.R.; et al. Cbfa1, a candidate gene for cleidocranial dysplasia syndrome, is essential for osteoblast differentiation and bone development. Cell 1997, 89, 765-771. [CrossRef]

91. Komori, T.; Yagi, H.; Nomura, S.; Yamaguchi, A.; Sasaki, K.; Deguchi, K.; Shimizu, Y.; Bronson, R.T.; Gao, Y.H.; Inada, M.; et al. Targeted disruption of Cbfa1 results in a complete lack of bone formation owing to maturational arrest of osteoblasts. Cell 1997, 89, 755-764. [CrossRef]

92. Sadikovic, B.; Thorner, P.; Chilton-Macneill, S.; Martin, J.W.; Cervigne, N.K.; Squire, J.; Zielenska, M. Expression analysis of genes associated with human osteosarcoma tumors shows correlation of RUNX2 overexpression with poor response to chemotherapy. Bmc Cancer 2010, 10, 202. [CrossRef] [PubMed]

93. Li, H.; Zhou, R.J.; Zhang, G.Q.; Xu, J.P. Clinical significance of RUNX2 expression in patients with nonsmall cell lung cancer: A 5-year follow-up study. Tumour Biol. J. Int. Soc. Oncodev. Biol. Med. 2013, 34, 1807-1812. [CrossRef] [PubMed]

94. Ferrari, N.; McDonald, L.; Morris, J.S.; Cameron, E.R.; Blyth, K. RUNX2 in mammary gland development and breast cancer. J. Cell. Physiol. 2013, 228, 1137-1142. [CrossRef] [PubMed] 
95. Stewart, M.; Terry, A.; Hu, M.; O’Hara, M.; Blyth, K.; Baxter, E.; Cameron, E.; Onions, D.E.; Neil, J.C. Proviral insertions induce the expression of bone-specific isoforms of PEBP2alphaA (CBFA1): Evidence for a new myc collaborating oncogene. Proc. Natl. Acad. Sci. USA 1997, 94, 8646-8651. [CrossRef]

96. Zhang, Y.; Xie, R.L.; Gordon, J.; LeBlanc, K.; Stein, J.L.; Lian, J.B.; van Wijnen, A.J.; Stein, G.S. Control of mesenchymal lineage progression by microRNAs targeting skeletal gene regulators Trps1 and Runx2. J. Biol. Chem. 2012, 287, 21926-21935. [CrossRef]

97. Wei, J.; Shi, Y.; Zheng, L.; Zhou, B.; Inose, H.; Wang, J.; Guo, X.E.; Grosschedl, R.; Karsenty, G. miR-34s inhibit osteoblast proliferation and differentiation in the mouse by targeting SATB2. J. Cell Biol. 2012, 197, 509-521. [CrossRef]

98. Taipaleenmaki, H.; Browne, G.; Akech, J.; Zustin, J.; van Wijnen, A.J.; Stein, J.L.; Hesse, E.; Stein, G.S.; Lian, J.B. Targeting of Runx2 by miR-135 and miR-203 Impairs Progression of Breast Cancer and Metastatic Bone Disease. Cancer Res. 2015, 75, 1433-1444. [CrossRef]

99. Chen, N.X.; Kiattisunthorn, K.; O’Neill, K.D.; Chen, X.; Moorthi, R.N.; Gattone, V.H., 2nd; Allen, M.R.; Moe, S.M. Decreased microRNA is involved in the vascular remodeling abnormalities in chronic kidney disease (CKD). PLoS ONE 2013, 8, e64558. [CrossRef]

100. Cohen, M.M., Jr. Perspectives on RUNX genes: An update. Am. J. Med. Genet. A 2009, 149A, $2629-2646$. [CrossRef]

101. Huang, K.; Fu, J.; Zhou, W.; Li, W.; Dong, S.; Yu, S.; Hu, Z.; Wang, H.; Xie, Z. MicroRNA-125b regulates osteogenic differentiation of mesenchymal stem cells by targeting Cbfbeta in vitro. Biochimie 2014, 102, 47-55. [CrossRef] [PubMed]

102. Mizuno, Y.; Yagi, K.; Tokuzawa, Y.; Kanesaki-Yatsuka, Y.; Suda, T.; Katagiri, T.; Fukuda, T.; Maruyama, M.; Okuda, A.; Amemiya, T.; et al. miR-125b inhibits osteoblastic differentiation by down-regulation of cell proliferation. Biochem. Biophys. Res. Commun. 2008, 368, 267-272. [CrossRef] [PubMed]

103. Goettsch, C.; Rauner, M.; Pacyna, N.; Hempel, U.; Bornstein, S.R.; Hofbauer, L.C. miR-125b regulates calcification of vascular smooth muscle cells. Am. J. Pathol. 2011, 179, 1594-1600. [CrossRef]

104. Lee, M.H.; Javed, A.; Kim, H.J.; Shin, H.I.; Gutierrez, S.; Choi, J.Y.; Rosen, V.; Stein, J.L.; van Wijnen, A.J.; Stein, G.S.; et al. Transient upregulation of CBFA1 in response to bone morphogenetic protein-2 and transforming growth factor beta1 in C2C12 myogenic cells coincides with suppression of the myogenic phenotype but is not sufficient for osteoblast differentiation. J. Cell. Biochem. 1999, 73, 114-125. [CrossRef]

105. Sun, Y.; Gui, T.; Shimokado, A.; Muragaki, Y. The Role of Tricho-Rhino-Phalangeal Syndrome (TRPS) 1 in Apoptosis during Embryonic Development and Tumor Progression. Cells 2013, 2, 496-505. [CrossRef] [PubMed]

106. Ordonez, N.G. SATB2 is a novel marker of osteoblastic differentiation and colorectal adenocarcinoma. Adv. Anat. Pathol. 2014, 21, 63-67. [CrossRef] [PubMed]

107. Conner, J.R.; Hornick, J.L. SATB2 is a novel marker of osteoblastic differentiation in bone and soft tissue tumours. Histopathology 2013, 63, 36-49. [CrossRef]

108. Tang, W.; Li, Y.; Osimiri, L.; Zhang, C. Osteoblast-specific transcription factor Osterix (Osx) is an upstream regulator of Satb2 during bone formation. J. Biol. Chem. 2011, 286, 32995-33002. [CrossRef]

109. Dobreva, G.; Chahrour, M.; Dautzenberg, M.; Chirivella, L.; Kanzler, B.; Farinas, I.; Karsenty, G.; Grosschedl, R. SATB2 is a multifunctional determinant of craniofacial patterning and osteoblast differentiation. Cell 2006, 125, 971-986. [CrossRef]

110. Kanzler, B.; Kuschert, S.J.; Liu, Y.H.; Mallo, M. Hoxa-2 restricts the chondrogenic domain and inhibits bone formation during development of the branchial area. Development 1998, 125, 2587-2597. [PubMed]

111. Simeone, A.; Acampora, D.; Pannese, M.; D’Esposito, M.; Stornaiuolo, A.; Gulisano, M.; Mallamaci, A.; Kastury, K.; Druck, T.; Huebner, K.; et al. Cloning and characterization of two members of the vertebrate Dlx gene family. Proc. Natl. Acad. Sci. USA 1994, 91, 2250-2254. [CrossRef] [PubMed]

112. Acampora, D.; Merlo, G.R.; Paleari, L.; Zerega, B.; Postiglione, M.P.; Mantero, S.; Bober, E.; Barbieri, O.; Simeone, A.; Levi, G. Craniofacial, vestibular and bone defects in mice lacking the Distal-less-related gene Dlx5. Development 1999, 126, 3795-3809. [PubMed]

113. Lee, M.H.; Kim, Y.J.; Yoon, W.J.; Kim, J.I.; Kim, B.G.; Hwang, Y.S.; Wozney, J.M.; Chi, X.Z.; Bae, S.C.; Choi, K.Y.; et al. Dlx5 specifically regulates Runx2 type II expression by binding to homeodomain-response elements in the Runx2 distal promoter. J. Biol. Chem. 2005, 280, 35579-35587. [CrossRef] [PubMed] 
114. Robledo, R.F.; Rajan, L.; Li, X.; Lufkin, T. The Dlx5 and Dlx6 homeobox genes are essential for craniofacial, axial, and appendicular skeletal development. Genes Dev. 2002, 16, 1089-1101. [CrossRef]

115. Yang, X.; Karsenty, G. Transcription factors in bone: Developmental and pathological aspects. Trends Mol. Med. 2002, 8, 340-345. [CrossRef]

116. Brubaker, K.D.; Vessella, R.L.; Brown, L.G.; Corey, E. Prostate cancer expression of runt-domain transcription factor Runx2, a key regulator of osteoblast differentiation and function. Prostate 2003, 56, 13-22. [CrossRef]

117. Momeni, P.; Glockner, G.; Schmidt, O.; von Holtum, D.; Albrecht, B.; Gillessen-Kaesbach, G.; Hennekam, R.; Meinecke, P.; Zabel, B.; Rosenthal, A.; et al. Mutations in a new gene, encoding a zinc-finger protein, cause tricho-rhino-phalangeal syndrome type I. Nat. Genet. 2000, 24, 71-74. [CrossRef]

118. Radvanyi, L.; Singh-Sandhu, D.; Gallichan, S.; Lovitt, C.; Pedyczak, A.; Mallo, G.; Gish, K.; Kwok, K.; Hanna, W.; Zubovits, J.; et al. The gene associated with trichorhinophalangeal syndrome in humans is overexpressed in breast cancer. Proc. Natl. Acad. Sci. USA 2005, 102, 11005-11010. [CrossRef]

119. Hong, J.; Sun, J.; Huang, T. Increased expression of TRPS1 affects tumor progression and correlates with patients' prognosis of colon cancer. Biomed. Res. Int. 2013, 2013, 454085. [CrossRef]

120. Piscopo, D.M.; Johansen, E.B.; Derynck, R. Identification of the GATA factor TRPS1 as a repressor of the osteocalcin promoter. J. Biol. Chem. 2009, 284, 31690-31703. [CrossRef]

121. Canalis, E.; Adams, D.J.; Boskey, A.; Parker, K.; Kranz, L.; Zanotti, S. Notch signaling in osteocytes differentially regulates cancellous and cortical bone remodeling. J. Biol. Chem. 2013, 288, 25614-25625. [CrossRef] [PubMed]

122. Tezuka, K.; Yasuda, M.; Watanabe, N.; Morimura, N.; Kuroda, K.; Miyatani, S.; Hozumi, N. Stimulation of osteoblastic cell differentiation by Notch. J. Bone Miner. Res. Off. J. Am. Soc. Bone Miner. Res. 2002, 17, 231-239. [CrossRef] [PubMed]

123. Sharff, K.A.; Song, W.X.; Luo, X.; Tang, N.; Luo, J.; Chen, J.; Bi, Y.; He, B.C.; Huang, J.; Li, X.; et al. Hey1 basic helix-loop-helix protein plays an important role in mediating BMP9-induced osteogenic differentiation of mesenchymal progenitor cells. J. Biol. Chem. 2009, 284, 649-659. [CrossRef] [PubMed]

124. Hilton, M.J.; Tu, X.; Wu, X.; Bai, S.; Zhao, H.; Kobayashi, T.; Kronenberg, H.M.; Teitelbaum, S.L.; Ross, F.P.; Kopan, R.; et al. Notch signaling maintains bone marrow mesenchymal progenitors by suppressing osteoblast differentiation. Nat. Med. 2008, 14, 306-314. [CrossRef]

125. Artavanis-Tsakonas, S.; Rand, M.D.; Lake, R.J. Notch signaling: Cell fate control and signal integration in development. Science 1999, 284, 770-776. [CrossRef]

126. Engin, F.; Bertin, T.; Ma, O.; Jiang, M.M.; Wang, L.; Sutton, R.E.; Donehower, L.A.; Lee, B. Notch signaling contributes to the pathogenesis of human osteosarcomas. Hum. Mol. Genet. 2009, 18, 1464-1470. [CrossRef]

127. Purow, B.W.; Haque, R.M.; Noel, M.W.; Su, Q.; Burdick, M.J.; Lee, J.; Sundaresan, T.; Pastorino, S.; Park, J.K.; Mikolaenko, I.; et al. Expression of Notch-1 and its ligands, Delta-like-1 and Jagged-1, is critical for glioma cell survival and proliferation. Cancer Res. 2005, 65, 2353-2363. [CrossRef]

128. Dotto, G.P. Crosstalk of Notch with p53 and p63 in cancer growth control. Nat. Rev. Cancer 2009, 9, 587-595. [CrossRef]

129. Pastorcic, M.; Das, H.K. Regulation of transcription of the human presenilin-1 gene by ets transcription factors and the p53 protooncogene. J. Biol. Chem. 2000, 275, 34938-34945. [CrossRef]

130. Bae, Y.; Yang, T.; Zeng, H.C.; Campeau, P.M.; Chen, Y.; Bertin, T.; Dawson, B.C.; Munivez, E.; Tao, J.; Lee, B.H. miRNA-34c regulates Notch signaling during bone development. Hum. Mol. Genet. 2012, 21, 2991-3000. [CrossRef]

131. Xu, M.; Jin, H.; Xu, C.X.; Bi, W.Z.; Wang, Y. MiR-34c inhibits osteosarcoma metastasis and chemoresistance. Med. Oncol. 2014, 31, 972. [CrossRef]

132. Sree, S.; Radhakrishnan, K.; Indu, S.; Kumar, P.G. Dramatic changes in 67 miRNAs during initiation of first wave of spermatogenesis in Mus musculus testis: Global regulatory insights generated by miRNA-mRNA network analysis. Biol. Reprod. 2014, 91, 69. [CrossRef]

133. Manca, S.; Magrelli, A.; Cialfi, S.; Lefort, K.; Ambra, R.; Alimandi, M.; Biolcati, G.; Uccelletti, D.; Palleschi, C.; Screpanti, I.; et al. Oxidative stress activation of miR-125b is part of the molecular switch for Hailey-Hailey disease manifestation. Exp. Dermatol. 2011, 20, 932-937. [CrossRef]

134. Bouhallier, F.; Allioli, N.; Lavial, F.; Chalmel, F.; Perrard, M.H.; Durand, P.; Samarut, J.; Pain, B.; Rouault, J.P. Role of miR-34c microRNA in the late steps of spermatogenesis. RNA 2010, 16, 720-731. [CrossRef] 
135. Hoesel, B.; Bhujabal, Z.; Przemeck, G.K.; Kurz-Drexler, A.; Weisenhorn, D.M.; Angelis, M.H.; Beckers, J. Combination of in silico and in situ hybridisation approaches to identify potential Dll1 associated miRNAs during mouse embryogenesis. Gene Expr. Patterns Gep 2010, 10, 265-273. [CrossRef]

136. Rawadi, G.; Vayssiere, B.; Dunn, F.; Baron, R.; Roman-Roman, S. BMP-2 controls alkaline phosphatase expression and osteoblast mineralization by a Wnt autocrine loop. J. Bone Min. Res. 2003, 18, 1842-1853. [CrossRef]

137. Mansukhani, A.; Ambrosetti, D.; Holmes, G.; Cornivelli, L.; Basilico, C. Sox2 induction by FGF and FGFR2 activating mutations inhibits Wnt signaling and osteoblast differentiation. J. Cell Biol. 2005, 168, 1065-1076. [CrossRef]

138. Thatcher, E.J.; Paydar, I.; Anderson, K.K.; Patton, J.G. Regulation of zebrafish fin regeneration by microRNAs. Proc. Natl. Acad. Sci. USA 2008, 105, 18384-18389. [CrossRef]

139. Mine, M.; Yamaguchi, K.; Sugiura, T.; Chigita, S.; Yoshihama, N.; Yoshihama, R.; Hiyake, N.; Kobayashi, Y.; Mori, Y. miR-203 Inhibits Frizzled-2 Expression via CD82/KAI1 Expression in Human Lung Carcinoma Cells. PLoS ONE 2015, 10, e0131350. [CrossRef]

140. Taube, J.H.; Malouf, G.G.; Lu, E.; Sphyris, N.; Vijay, V.; Ramachandran, P.P.; Ueno, K.R.; Gaur, S.; Nicoloso, M.S.; Rossi, S.; et al. Epigenetic silencing of microRNA-203 is required for EMT and cancer stem cell properties. Sci. Rep. 2013, 3, 2687. [CrossRef]

141. Lee, N.; Smolarz, A.J.; Olson, S.; David, O.; Reiser, J.; Kutner, R.; Daw, N.C.; Prockop, D.J.; Horwitz, E.M.; Gregory, C.A. A potential role for Dkk-1 in the pathogenesis of osteosarcoma predicts novel diagnostic and treatment strategies. Br. J. Cancer 2007, 97, 1552-1559. [CrossRef]

142. Iyer, S.; Ambrogini, E.; Bartell, S.M.; Han, L.; Roberson, P.K.; de Cabo, R.; Jilka, R.L.; Weinstein, R.S.; O'Brien, C.A.; Manolagas, S.C.; et al. FOXOs attenuate bone formation by suppressing Wnt signaling. J. Clin. Investig. 2013, 123, 3409-3419. [CrossRef]

143. Matsumoto, T.; Kuriwaka-Kido, R.; Kondo, T.; Endo, I.; Kido, S. Regulation of osteoblast differentiation by interleukin-11 via AP-1 and Smad signaling. Endocr. J. 2012, 59, 91-101. [CrossRef]

144. Tripathi, A.K.; Dwivedi, A.; Pal, M.K.; Rastogi, N.; Gupta, P.; Ali, S.; Prabhu, M.B.; Kushwaha, H.N.; Ray, R.S.; Singh, S.K.; et al. Attenuated neuroprotective effect of riboflavin under UV-B irradiation via miR-203/c-Jun signaling pathway in vivo and in vitro. J. Biomed. Sci. 2014, 21, 39. [CrossRef]

145. Luo, W.; Wu, H.; Ye, Y.; Li, Z.; Hao, S.; Kong, L.; Zheng, X.; Lin, S.; Nie, Q.; Zhang, X. The transient expression of miR-203 and its inhibiting effects on skeletal muscle cell proliferation and differentiation. Cell Death Dis. 2014, 5, e1347. [CrossRef]

146. Stecca, B.; Ruiz i Altaba, A. A GLI1-p53 inhibitory loop controls neural stem cell and tumour cell numbers. Embo J. 2009, 28, 663-676. [CrossRef]

147. Abe, Y.; Oda-Sato, E.; Tobiume, K.; Kawauchi, K.; Taya, Y.; Okamoto, K.; Oren, M.; Tanaka, N. Hedgehog signaling overrides p53-mediated tumor suppression by activating Mdm2. Proc. Natl. Acad. Sci. USA 2008, 105, 4838-4843. [CrossRef]

148. Duan, X.; Murata, Y.; Liu, Y.; Nicolae, C.; Olsen, B.R.; Berendsen, A.D. Vegfa regulates perichondrial vascularity and osteoblast differentiation in bone development. Development 2015, 142, 1984-1991. [CrossRef]

149. Ducy, P.; Zhang, R.; Geoffroy, V.; Ridall, A.L.; Karsenty, G. Osf2/Cbfa1: A transcriptional activator of osteoblast differentiation. Cell 1997, 89, 747-754. [CrossRef]

150. Heldin, C.H.; Miyazono, K.; ten Dijke, P. TGF-beta signalling from cell membrane to nucleus through SMAD proteins. Nature 1997, 390, 465-471. [CrossRef]

151. Chang, S.F.; Chang, T.K.; Peng, H.H.; Yeh, Y.T.; Lee, D.Y.; Yeh, C.R.; Zhou, J.; Cheng, C.K.; Chang, C.A.; Chiu, J.J. BMP-4 induction of arrest and differentiation of osteoblast-like cells via p21 CIP1 and p27 KIP1 regulation. Mol. Endocrinol. 2009, 23, 1827-1838. [CrossRef]

152. Bandyopadhyay, A.; Tsuji, K.; Cox, K.; Harfe, B.D.; Rosen, V.; Tabin, C.J. Genetic analysis of the roles of BMP2, BMP4, and BMP7 in limb patterning and skeletogenesis. PLoS Genet. 2006, 2, e216. [CrossRef]

153. Fotinos, A.; Nagarajan, N.; Martins, A.S.; Fritz, D.T.; Garsetti, D.; Lee, A.T.; Hong, C.C.; Rogers, M.B. Bone morphogenetic protein-focused strategies to induce cytotoxicity in lung cancer cells. Anticancer Res. 2014, 34, 2095-2104.

154. Cao, H.; Jheon, A.; Li, X.; Sun, Z.; Wang, J.; Florez, S.; Zhang, Z.; McManus, M.T.; Klein, O.D.; Amendt, B.A. The Pitx2:miR-200c/141:noggin pathway regulates Bmp signaling and ameloblast differentiation. Development 2013, 140, 3348-3359. [CrossRef] 
155. Heinke, J.; Kerber, M.; Rahner, S.; Mnich, L.; Lassmann, S.; Helbing, T.; Werner, M.; Patterson, C.; Bode, C.; Moser, M. Bone morphogenetic protein modulator BMPER is highly expressed in malignant tumors and controls invasive cell behavior. Oncogene 2012, 31, 2919-2930. [CrossRef]

156. Rentzsch, F.; Zhang, J.; Kramer, C.; Sebald, W.; Hammerschmidt, M. Crossveinless 2 is an essential positive feedback regulator of Bmp signaling during zebrafish gastrulation. Development 2006, 133, 801-811. [CrossRef]

157. Padua, D.; Zhang, X.H.; Wang, Q.; Nadal, C.; Gerald, W.L.; Gomis, R.R.; Massague, J. TGFbeta primes breast tumors for lung metastasis seeding through angiopoietin-like 4. Cell 2008, 133, 66-77. [CrossRef]

158. Zhang, R.; Edwards, J.R.; Ko, S.Y.; Dong, S.; Liu, H.; Oyajobi, B.O.; Papasian, C.; Deng, H.W.; Zhao, M. Transcriptional regulation of BMP2 expression by the PTH-CREB signaling pathway in osteoblasts. PLOS ONE 2011, 6, e20780. [CrossRef]

159. Noguchi, S.; Kumazaki, M.; Mori, T.; Baba, K.; Okuda, M.; Mizuno, T.; Akao, Y. Analysis of microRNA-203 function in CREB/MITF/RAB27a pathway: Comparison between canine and human melanoma cells. Vet. Comp. Oncol. 2014. [CrossRef]

160. Benaich, N.; Woodhouse, S.; Goldie, S.J.; Mishra, A.; Quist, S.R.; Watt, F.M. Rewiring of an epithelial differentiation factor, miR-203, to inhibit human squamous cell carcinoma metastasis. Cell Rep. 2014, 9, 104-117. [CrossRef]

161. Rosset, E.M.; Bradshaw, A.D. SPARC/osteonectin in mineralized tissue. Matrix Biol. 2016. [CrossRef]

162. Sato, C.; Iwasaki, T.; Kitano, S.; Tsunemi, S.; Sano, H. Sphingosine 1-phosphate receptor activation enhances BMP-2-induced osteoblast differentiation. Biochem. Biophys. Res. Commun. 2012, 423, 200-205. [CrossRef]

163. Li, Q.; Pan, Z.; Wang, X.; Gao, Z.; Ren, C.; Yang, W. miR-125b-1-3p inhibits trophoblast cell invasion by targeting sphingosine-1-phosphate receptor 1 in preeclampsia. Biochem. Biophys. Res. Commun. 2014, 453, 57-63. [CrossRef]

164. Wu, L.; Belasco, J.G. Micro-RNA regulation of the mammalian lin-28 gene during neuronal differentiation of embryonal carcinoma cells. Mol. Cell. Biol. 2005, 25, 9198-9208. [CrossRef] [PubMed]

165. Ma, W.; Ma, J.; Xu, J.; Qiao, C.; Branscum, A.; Cardenas, A.; Baron, A.T.; Schwartz, P.; Maihle, N.J.; Huang, Y. Lin28 regulates BMP4 and functions with Oct4 to affect ovarian tumor microenvironment. Cell Cycle 2013, 12, 88-97. [CrossRef] [PubMed]

166. Zhang, Z.J.; Zhang, H.; Kang, Y.; Sheng, P.Y.; Ma, Y.C.; Yang, Z.B.; Zhang, Z.Q.; Fu, M.; He, A.S.; Liao, W.M. miRNA expression profile during osteogenic differentiation of human adipose-derived stem cells. J. Cell. Biochem. 2012, 113, 888-898. [CrossRef] [PubMed]

167. Saita, Y.; Takagi, T.; Kitahara, K.; Usui, M.; Miyazono, K.; Ezura, Y.; Nakashima, K.; Kurosawa, H.; Ishii, S.; Noda, M. Lack of Schnurri-2 expression associates with reduced bone remodeling and osteopenia. J. Biol. Chem. 2007, 282, 12907-12915. [CrossRef]

168. Lin, R.L.; Zhao, L.J. Mechanistic basis and clinical relevance of the role of transforming growth factor-beta in cancer. Cancer Biol. Med. 2015, 12, 385-393. [CrossRef]

169. Alliston, T.; Choy, L.; Ducy, P.; Karsenty, G.; Derynck, R. TGF-beta-induced repression of CBFA1 by Smad3 decreases cbfa1 and osteocalcin expression and inhibits osteoblast differentiation. Embo J. 2001, 20, 2254-2272. [CrossRef]

170. Rana, T.; Chakrabarti, A.; Freeman, M.; Biswas, S. Doxorubicin-mediated bone loss in breast cancer bone metastases is driven by an interplay between oxidative stress and induction of TGFbeta. PLoS ONE 2013, 8, e78043. [CrossRef]

171. Maeda, S.; Hayashi, M.; Komiya, S.; Imamura, T.; Miyazono, K. Endogenous TGF-beta signaling suppresses maturation of osteoblastic mesenchymal cells. Embo J. 2004, 23, 552-563. [CrossRef]

172. Emmrich, S.; Rasche, M.; Schoning, J.; Reimer, C.; Keihani, S.; Maroz, A.; Xie, Y.; Li, Z.; Schambach, A.; Reinhardt, D.; et al. miR-99a/100 125b tricistrons regulate hematopoietic stem and progenitor cell homeostasis by shifting the balance between TGFbeta and Wnt signaling. Genes Dev. 2014, 28, 858-874. [CrossRef]

173. Zhou, J.N.; Zeng, Q.; Wang, H.Y.; Zhang, B.; Li, S.T.; Nan, X.; Cao, N.; Fu, C.J.; Yan, X.L.; Jia, Y.L.; et al. MicroRNA-125b attenuates epithelial-mesenchymal transitions and targets stem-like liver cancer cells through small mothers against decapentaplegic 2 and 4. Hepatology 2015, 62, 801-815. [CrossRef]

174. Du, X.; Xie, Y.; Xian, C.J.; Chen, L. Role of FGFs/FGFRs in skeletal development and bone regeneration. J. Cell. Physiol. 2012, 227, 3731-3743. [CrossRef]

175. Singh, S.; Singh, M.; Mak, I.W.; Turcotte, R.; Ghert, M. Investigation of FGFR2-IIIC signaling via FGF-2 ligand for advancing GCT stromal cell differentiation. PLoS ONE 2012, 7, e46769. [CrossRef] 
176. Eswarakumar, V.P.; Monsonego-Ornan, E.; Pines, M.; Antonopoulou, I.; Morriss-Kay, G.M.; Lonai, P. The IIIc alternative of Fgfr2 is a positive regulator of bone formation. Development 2002, 129, 3783-3793.

177. Zhou, W.; Zhu, Y.; Chen, S.; Xu, R.; Wang, K. Fibroblast growth factor receptor 1 promotes MG63 cell proliferation and is associated with increased expression of cyclin-dependent kinase 1 in osteosarcoma. Mol. Med. Rep. 2016, 13, 713-719. [CrossRef]

178. Xu, M.; Gu, M.; Zhang, K.; Zhou, J.; Wang, Z.; Da, J. miR-203 inhibition of renal cancer cell proliferation, migration and invasion by targeting of FGF2. Diagn. Pathol. 2015, 10, 24. [CrossRef]

179. Miraoui, H.; Oudina, K.; Petite, H.; Tanimoto, Y.; Moriyama, K.; Marie, P.J. Fibroblast growth factor receptor 2 promotes osteogenic differentiation in mesenchymal cells via ERK1/2 and protein kinase C signaling. J. Biol. Chem. 2009, 284, 4897-4904. [CrossRef]

180. Wang, C.; Wang, X.; Liang, H.; Wang, T.; Yan, X.; Cao, M.; Wang, N.; Zhang, S.; Zen, K.; Zhang, C.; et al. miR-203 Inhibits Cell Proliferation and Migration of Lung Cancer Cells by Targeting PKCalpha. PLoS ONE 2013, 8, e73985. [CrossRef]

181. Cao, S.E.; Tian, J.; Chen, S.; Zhang, X.; Zhang, Y. Role of miR-34c in ketamine-induced neurotoxicity in neonatal mice hippocampus. Cell Biol. Int. 2015, 39, 164-168. [CrossRef]

182. Fisher, M.C.; Clinton, G.M.; Maihle, N.J.; Dealy, C.N. Requirement for ErbB2/ErbB signaling in developing cartilage and bone. Dev. Growth Differ. 2007, 49, 503-513. [CrossRef]

183. Guan, H.; Jia, S.F.; Zhou, Z.; Stewart, J.; Kleinerman, E.S. Herceptin down-regulates HER-2/neu and vascular endothelial growth factor expression and enhances taxol-induced cytotoxicity of human Ewing's sarcoma cells in vitro and in vivo. Clin. Cancer Res. Off. J. Am. Assoc. Cancer Res. 2005, 11, 2008-2017. [CrossRef]

184. Scott, G.K.; Goga, A.; Bhaumik, D.; Berger, C.E.; Sullivan, C.S.; Benz, C.C. Coordinate suppression of ERBB2 and ERBB3 by enforced expression of micro-RNA miR-125a or miR-125b. J. Biol. Chem. 2007, 282, 1479-1486. [CrossRef]

185. Zhou, S.; Zhang, P.; Liang, P.; Huang, X. The expression of miR-125b regulates angiogenesis during the recovery of heat-denatured HUVECs. Burns 2015, 41, 803-811. [CrossRef]

186. Yagishita, S.; Fujita, Y.; Kitazono, S.; Ko, R.; Nakadate, Y.; Sawada, T.; Kitamura, Y.; Shimoyama, T.; Maeda, Y.; Takahashi, F.; et al. Chemotherapy-Regulated microRNA-125-HER2 Pathway as a Novel Therapeutic Target for Trastuzumab-Mediated Cellular Cytotoxicity in Small Cell Lung Cancer. Mol. Cancer 2015, 14, 1414-1423. [CrossRef]

187. Itoh, S.; Udagawa, N.; Takahashi, N.; Yoshitake, F.; Narita, H.; Ebisu, S.; Ishihara, K. A critical role for interleukin-6 family-mediated Stat 3 activation in osteoblast differentiation and bone formation. Bone 2006, 39, 505-512. [CrossRef]

188. Nicolaidou, V.; Wong, M.M.; Redpath, A.N.; Ersek, A.; Baban, D.F.; Williams, L.M.; Cope, A.P.; Horwood, N.J. Monocytes induce STAT3 activation in human mesenchymal stem cells to promote osteoblast formation. PLOS ONE 2012, 7, e39871. [CrossRef]

189. Bellido, T.; O’Brien, C.A.; Roberson, P.K.; Manolagas, S.C. Transcriptional activation of the p21(WAF1,CIP1,SDI1) gene by interleukin-6 type cytokines. A prerequisite for their pro-differentiating and anti-apoptotic effects on human osteoblastic cells. J. Biol. Chem. 1998, 273, 21137-21144. [CrossRef]

190. Surdziel, E.; Cabanski, M.; Dallmann, I.; Lyszkiewicz, M.; Krueger, A.; Ganser, A.; Scherr, M.; Eder, M. Enforced expression of miR-125b affects myelopoiesis by targeting multiple signaling pathways. Blood 2011, 117, 4338-4348. [CrossRef]

191. Bromberg, J.F.; Wrzeszczynska, M.H.; Devgan, G.; Zhao, Y.; Pestell, R.G.; Albanese, C.; Darnell, J.E., Jr. Stat3 as an oncogene. Cell 1999, 98, 295-303. [CrossRef]

192. Guicheux, J.; Lemonnier, J.; Ghayor, C.; Suzuki, A.; Palmer, G.; Caverzasio, J. Activation of p38 mitogen-activated protein kinase and c-Jun-NH2-terminal kinase by BMP-2 and their implication in the stimulation of osteoblastic cell differentiation. J. Bone Miner. Res. Off. J. Am. Soc. Bone Miner. Res. 2003, 18, 2060-2068. [CrossRef] [PubMed]

193. Wu, Y.; Zhou, J.; Li, Y.; Zhou, Y.; Cui, Y.; Yang, G.; Hong, Y. Rap1A Regulates Osteoblastic Differentiation via the ERK and p38 Mediated Signaling. PLoS ONE 2015, 10, e0143777. [CrossRef]

194. Tan, G.; Niu, J.; Shi, Y.; Ouyang, H.; Wu, Z.H. NF-kappaB-dependent microRNA-125b up-regulation promotes cell survival by targeting p38alpha upon ultraviolet radiation. J. Biol. Chem. 2012, 287, 33036-33047. [CrossRef] 
195. Xiang, J.; Bian, C.; Wang, H.; Huang, S.; Wu, D. MiR-203 down-regulates Rap1A and suppresses cell proliferation, adhesion and invasion in prostate cancer. J. Exp. Clin. Cancer Res. 2015, 34, 8. [CrossRef]

196. Pannem, R.R.; Dorn, C.; Ahlqvist, K.; Bosserhoff, A.K.; Hellerbrand, C.; Massoumi, R. CYLD controls c-MYC expression through the JNK-dependent signaling pathway in hepatocellular carcinoma. Carcinogenesis 2014, 35, 461-468. [CrossRef]

197. Piek, E.; Sleumer, L.S.; van Someren, E.P.; Heuver, L.; de Haan, J.R.; de Grijs, I.; Gilissen, C.; Hendriks, J.M.; van Ravestein-van Os, R.I.; Bauerschmidt, S.; et al. Osteo-transcriptomics of human mesenchymal stem cells: Accelerated gene expression and osteoblast differentiation induced by vitamin D reveals c-MYC as an enhancer of BMP2-induced osteogenesis. Bone 2010, 46, 613-627. [CrossRef]

198. Cannell, I.G.; Kong, Y.W.; Johnston, S.J.; Chen, M.L.; Collins, H.M.; Dobbyn, H.C.; Elia, A.; Kress, T.R.; Dickens, M.; Clemens, M.J.; et al. p38 MAPK/MK2-mediated induction of miR-34c following DNA damage prevents Myc-dependent DNA replication. Proc. Natl. Acad. Sci. USA 2010, 107, 5375-5380. [CrossRef]

199. Knackmuss, U.; Lindner, S.E.; Aneichyk, T.; Kotkamp, B.; Knust, Z.; Villunger, A.; Herzog, S. MAP3K11 is a tumor suppressor targeted by the oncomiR miR-125b in early B cells. Cell Death Differ. 2016, 23, 242-252. [CrossRef]

200. Cai, T.; Yao, T.; Zheng, G.; Chen, Y.; Du, K.; Cao, Y.; Shen, X.; Chen, J.; Luo, W. Manganese induces the overexpression of alpha-synuclein in PC12 cells via ERK activation. Brain Res. 2010, 1359, 201-207. [CrossRef]

201. Fujita, M.; Sugama, S.; Nakai, M.; Takenouchi, T.; Wei, J.; Urano, T.; Inoue, S.; Hashimoto, M. alpha-Synuclein stimulates differentiation of osteosarcoma cells: Relevance to down-regulation of proteasome activity. J. Biol. Chem. 2007, 282, 5736-5748. [CrossRef]

202. Kabaria, S.; Choi, D.C.; Chaudhuri, A.D.; Mouradian, M.M.; Junn, E. Inhibition of miR-34b and miR-34c enhances alpha-synuclein expression in Parkinson's disease. FEBS Lett. 2015, 589, 319-325. [CrossRef]

203. Li, B.; Boast, S.; de los Santos, K.; Schieren, I.; Quiroz, M.; Teitelbaum, S.L.; Tondravi, M.M.; Goff, S.P. Mice deficient in $\mathrm{Abl}$ are osteoporotic and have defects in osteoblast maturation. Nat. Genet. 2000, 24, 304-308. [CrossRef]

204. Liao, G.; Panettieri, R.A.; Tang, D.D. MicroRNA-203 negatively regulates c-Abl, ERK1/2 phosphorylation, and proliferation in smooth muscle cells. Physiol. Rep. 2015, 3. [CrossRef]

205. Choi, Y.H.; Han, Y.; Lee, S.H.; Cheong, H.; Chun, K.H.; Yeo, C.Y.; Lee, K.Y. Src enhances osteogenic differentiation through phosphorylation of Osterix. Mol. Cell. Endocrinol. 2015, 407, 85-97. [CrossRef]

206. Wang, N.; Liang, H.; Zhou, Y.; Wang, C.; Zhang, S.; Pan, Y.; Wang, Y.; Yan, X.; Zhang, J.; Zhang, C.Y.; et al. miR-203 suppresses the proliferation and migration and promotes the apoptosis of lung cancer cells by targeting SRC. PLoS ONE 2014, 9, e105570. [CrossRef]

207. Rasheed, N.; Wang, X.; Niu, Q.T.; Yeh, J.; Li, B. Atm-deficient mice: An osteoporosis model with defective osteoblast differentiation and increased osteoclastogenesis. Hum. Mol. Genet. 2006, 15, 1938-1948. [CrossRef]

208. Rondeau, S.; Vacher, S.; De Koning, L.; Briaux, A.; Schnitzler, A.; Chemlali, W.; Callens, C.; Lidereau, R.; Bieche, I. ATM has a major role in the double-strand break repair pathway dysregulation in sporadic breast carcinomas and is an independent prognostic marker at both mRNA and protein levels. Br. J. Cancer 2015, 112, 1059-1066. [CrossRef]

209. Eyerich, S.; Wagener, J.; Wenzel, V.; Scarponi, C.; Pennino, D.; Albanesi, C.; Schaller, M.; Behrendt, H.; Ring, J.; Schmidt-Weber, C.B.; et al. IL-22 and TNF-alpha represent a key cytokine combination for epidermal integrity during infection with Candida albicans. Eur. J. Immunol. 2011, 41, 1894-1901. [CrossRef]

210. Wang, Y.W.; Xu, D.P.; Liu, Y.; Zhang, R.; Lu, L. The Effect of Tumor Necrosis Factor-alpha at Different Concentrations on Osteogenetic Differentiation of Bone Marrow Mesenchymal Stem Cells. J. Craniofacial Surg. 2015, 26, 2081-2085. [CrossRef]

211. Kim, J.K.; Jang, S.W.; Suk, K.; Lee, W.H. Fascin regulates TLR4/PKC-mediated translational activation through miR-155 and miR-125b, which targets the $3^{\prime}$ untranslated region of TNF-alpha mRNA. Immunol. Investig. 2015, 44, 309-320. [CrossRef] [PubMed]

212. Kato-Kogoe, N.; Nishioka, T.; Kawabe, M.; Kataoka, F.; Yamanegi, K.; Yamada, N.; Hata, M.; Yamamoto, T.; Nakasho, K.; Urade, M.; et al. The promotional effect of IL-22 on mineralization activity of periodontal ligament cells. Cytokine 2012, 59, 41-48. [CrossRef] [PubMed]

213. Shen, Z.; Du, G.; Zhou, Z.; Liu, W.; Shi, L.; Xu, H. Aberrant expression of interleukin-22 and its targeting microRNAs in oral lichen planus: A preliminary study. J. Oral Pathol. Med. 2015. [CrossRef] [PubMed] 
214. Dani, N.; Olivero, M.; Mareschi, K.; van Duist, M.M.; Miretti, S.; Cuvertino, S.; Patane, S.; Calogero, R.; Ferracini, R.; Scotlandi, K.; et al. The MET oncogene transforms human primary bone-derived cells into osteosarcomas by targeting committed osteo-progenitors. J. Bone Min. Res. 2012, 27, 1322-1334. [CrossRef]

215. Moumen, A.; Patane, S.; Porras, A.; Dono, R.; Maina, F. Met acts on Mdm2 via mTOR to signal cell survival during development. Development 2007, 134, 1443-1451. [CrossRef]

216. Arai, M.; Shibata, Y.; Pugdee, K.; Abiko, Y.; Ogata, Y. Effects of reactive oxygen species (ROS) on antioxidant system and osteoblastic differentiation in MC3T3-E1 cells. Iubmb Life 2007, 59, 27-33. [CrossRef]

217. Feng, Y.L.; Tang, X.L. Effect of glucocorticoid-induced oxidative stress on the expression of Cbfa1. Chem. -Biol. Interact. 2014, 207, 26-31. [CrossRef]

218. Bai, X.C.; Lu, D.; Bai, J.; Zheng, H.; Ke, Z.Y.; Li, X.M.; Luo, S.Q. Oxidative stress inhibits osteoblastic differentiation of bone cells by ERK and NF-kappaB. Biochem. Biophys. Res. Commun. 2004, 314, 197-207. [CrossRef]

219. Shah, N.M.; Zaitseva, L.; Bowles, K.M.; MacEwan, D.J.; Rushworth, S.A. NRF2-driven miR-125B1 and miR-29B1 transcriptional regulation controls a novel anti-apoptotic miRNA regulatory network for AML survival. Cell Death Differ. 2015, 22, 654-664. [CrossRef]

220. Hinoi, E.; Fujimori, S.; Wang, L.; Hojo, H.; Uno, K.; Yoneda, Y. Nrf2 negatively regulates osteoblast differentiation via interfering with Runx2-dependent transcriptional activation. J. Biol. Chem. 2006, 281, 18015-18024. [CrossRef]

221. Haemmig, S.; Baumgartner, U.; Gluck, A.; Zbinden, S.; Tschan, M.P.; Kappeler, A.; Mariani, L.; Vajtai, I.; Vassella, E. miR-125b controls apoptosis and temozolomide resistance by targeting TNFAIP3 and NKIRAS2 in glioblastomas. Cell Death Dis. 2014, 5, e1279. [CrossRef]

222. Luna, C.; Li, G.; Qiu, J.; Epstein, D.L.; Gonzalez, P. Role of miR-29b on the regulation of the extracellular matrix in human trabecular meshwork cells under chronic oxidative stress. Mol. Vis. 2009, 15, 2488-2497.

223. Soltanoff, C.S.; Yang, S.; Chen, W.; Li, Y.P. Signaling networks that control the lineage commitment and differentiation of bone cells. Crit. Rev. Eukaryot. Gene Expr. 2009, 19, 1-46. [CrossRef]

224. Guan, Y.; Yao, H.; Zheng, Z.; Qiu, G.; Sun, K. MiR-125b targets BCL3 and suppresses ovarian cancer proliferation. Int. J. Cancer 2011, 128, 2274-2283. [CrossRef]

225. Cho, H.H.; Shin, K.K.; Kim, Y.J.; Song, J.S.; Kim, J.M.; Bae, Y.C.; Kim, C.D.; Jung, J.S. NF-kappaB activation stimulates osteogenic differentiation of mesenchymal stem cells derived from human adipose tissue by increasing TAZ expression. J. Cell. Physiol. 2010, 223, 168-177. [CrossRef]

226. Li, J.; Fang, L.; Yu, W.; Wang, Y. MicroRNA-125b suppresses the migration and invasion of hepatocellular carcinoma cells by targeting transcriptional coactivator with PDZ-binding motif. Oncol. Lett. 2015, 9, 1971-1975. [CrossRef]

227. Yang, L.; Wu, Z.; Yin, G.; Liu, H.; Guan, X.; Zhao, X.; Wang, J.; Zhu, J. Stem cell factor (SCF) protects osteoblasts from oxidative stress through activating c-Kit-Akt signaling. Biochem. Biophys. Res. Commun. 2014, 455, 256-261. [CrossRef]

228. Choe, N.; Kwon, J.S.; Kim, Y.S.; Eom, G.H.; Ahn, Y.K.; Baik, Y.H.; Park, H.Y.; Kook, H. The microRNA miR-34c inhibits vascular smooth muscle cell proliferation and neointimal hyperplasia by targeting stem cell factor. Cell Signal. 2015, 27, 1056-1065. [CrossRef]

229. Niu, D.F.; Kondo, T.; Nakazawa, T.; Oishi, N.; Kawasaki, T.; Mochizuki, K.; Yamane, T.; Katoh, R. Transcription factor Runx2 is a regulator of epithelial-mesenchymal transition and invasion in thyroid carcinomas. Lab. Investig. 2012, 92, 1181-1190. [CrossRef]

230. Li, H.; Song, F.; Chen, X.; Li, Y.; Fan, J.; Wu, X. Bmi-1 regulates epithelial-to-mesenchymal transition to promote migration and invasion of breast cancer cells. Int. J. Clin. Exp. Pathol. 2014, 7, 3057-3064.

231. Douglas, D.; Hsu, J.H.; Hung, L.; Cooper, A.; Abdueva, D.; van Doorninck, J.; Peng, G.; Shimada, H.; Triche, T.J.; Lawlor, E.R. BMI-1 promotes ewing sarcoma tumorigenicity independent of CDKN2A repression. Cancer Res. 2008, 68, 6507-6515. [CrossRef] [PubMed]

232. Zhang, H.W.; Ding, J.; Jin, J.L.; Guo, J.; Liu, J.N.; Karaplis, A.; Goltzman, D.; Miao, D. Defects in mesenchymal stem cell self-renewal and cell fate determination lead to an osteopenic phenotype in Bmi-1 null mice. J. Bone Min. Res. 2010, 25, 640-652. [CrossRef] [PubMed]

233. Wellner, U.; Schubert, J.; Burk, U.C.; Schmalhofer, O.; Zhu, F.; Sonntag, A.; Waldvogel, B.; Vannier, C.; Darling, D.; zur Hausen, A.; et al. The EMT-activator ZEB1 promotes tumorigenicity by repressing stemness-inhibiting microRNAs. Nat. Cell Biol. 2009, 11, 1487-1495. [CrossRef] 
234. Wu, Z.; Min, L.; Chen, D.; Hao, D.; Duan, Y.; Qiu, G.; Wang, Y. Overexpression of BMI-1 promotes cell growth and resistance to cisplatin treatment in osteosarcoma. PLoS ONE 2011, 6, e14648. [CrossRef]

235. Yin, J.; Zheng, G.; Jia, X.; Zhang, Z.; Zhang, W.; Song, Y.; Xiong, Y.; He, Z. A Bmi1-miRNAs Cross-Talk Modulates Chemotherapy Response to 5-Fluorouracil in Breast Cancer Cells. PLoS ONE 2013, 8, e73268. [CrossRef] [PubMed]

236. Vandewalle, C.; Comijn, J.; De Craene, B.; Vermassen, P.; Bruyneel, E.; Andersen, H.; Tulchinsky, E.; Van Roy, F.; Berx, G. SIP1/ZEB2 induces EMT by repressing genes of different epithelial cell-cell junctions. Nucleic Acids Res. 2005, 33, 6566-6578. [CrossRef] [PubMed]

237. Lambertini, E.; Lisignoli, G.; Torreggiani, E.; Manferdini, C.; Gabusi, E.; Franceschetti, T.; Penolazzi, L.; Gambari, R.; Facchini, A.; Piva, R. Slug gene expression supports human osteoblast maturation. Cell Mol. Life Sci. 2009, 66, 3641-3653. [CrossRef]

238. Shi, Y.; Tan, Y.J.; Zeng, D.Z.; Qian, F.; Yu, P.W. miR-203 suppression in gastric carcinoma promotes Slug-mediated cancer metastasis. Tumour Biol. 2015. [CrossRef]

239. Wu, D.; Ding, J.; Wang, L.; Pan, H.; Zhou, Z.; Zhou, J.; Qu, P. microRNA-125b inhibits cell migration and invasion by targeting matrix metallopeptidase 13 in bladder cancer. Oncol. Lett. 2013, 5, 829-834. [CrossRef]

240. Ortiz, J.; Chou, L.L. Calcium upregulated survivin expression and associated osteogenesis of normal human osteoblasts. J. Biomed. Mater. Res. A 2012, 100, 1770-1776. [CrossRef]

241. Zhang, X.; Zhang, Y.; Liu, X.; Fang, A.; Li, P.; Li, Z.; Liu, T.; Yang, Y.; Du, L.; Wang, C. MicroRNA-203 Is a Prognostic Indicator in Bladder Cancer and Enhances Chemosensitivity to Cisplatin via Apoptosis by Targeting Bcl-w and Survivin. PLoS ONE 2015, 10, e0143441. [CrossRef] [PubMed]

242. Lim, M.; Zhong, C.; Yang, S.; Bell, A.M.; Cohen, M.B.; Roy-Burman, P. Runx2 regulates survivin expression in prostate cancer cells. Lab. Investig. 2010, 90, 222-233. [CrossRef] [PubMed]

243. Ji, Q.; Hao, X.; Meng, Y.; Zhang, M.; Desano, J.; Fan, D.; Xu, L. Restoration of tumor suppressor miR-34 inhibits human p53-mutant gastric cancer tumorspheres. Bmc Cancer 2008, 8, 266. [CrossRef] [PubMed]

244. Browne, G.; Nesbitt, H.; Ming, L.; Stein, G.S.; Lian, J.B.; McKeown, S.R.; Worthington, J. Bicalutamide-induced hypoxia potentiates RUNX2-mediated Bcl-2 expression resulting in apoptosis resistance. Br. J. Cancer 2012, 107, 1714-1721. [CrossRef] [PubMed]

245. Nagase, Y.; Iwasawa, M.; Akiyama, T.; Kadono, Y.; Nakamura, M.; Oshima, Y.; Yasui, T.; Matsumoto, T.; Hirose, J.; Nakamura, H.; et al. Anti-apoptotic molecule Bcl-2 regulates the differentiation, activation, and survival of both osteoblasts and osteoclasts. J. Biol. Chem. 2009, 284, 36659-36669. [CrossRef] [PubMed]

246. Zhang, K.; Dai, L.; Zhang, B.; Xu, X.; Shi, J.; Fu, L.; Chen, X.; Li, J.; Bai, Y. miR-203 is a direct transcriptional target of E2F1 and causes G1 arrest in esophageal cancer cells. J. Cell Physiol. 2015, 230, 903-910. [CrossRef]

247. Yuan, J.M.; Shi, X.J.; Sun, P.; Liu, J.X.; Wang, W.; Li, M.; Ling, F.Y. Downregulation of cell cycle-related proteins in ovarian cancer line and cell cycle arrest induced by microRNA. Int. J. Clin. Exp. Med. 2015, 8, 18476-18481. [PubMed]

248. Qiu, W.; Kassem, M. miR-141-3p inhibits human stromal (mesenchymal) stem cell proliferation and differentiation. Biochim. Biophys. Acta 2014, 1843, 2114-2121. [CrossRef]

(C) 2020 by the authors. Licensee MDPI, Basel, Switzerland. This article is an open access article distributed under the terms and conditions of the Creative Commons Attribution (CC BY) license (http://creativecommons.org/licenses/by/4.0/). 